\title{
$30+$ years of media analysis of relevance to chronic disease: a scoping review
}

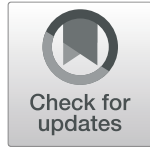

Samantha Rowbotham ${ }^{1,2^{*}}$, Thomas Astell-Burt ${ }^{1,3,4,5}$, Tala Barakat ${ }^{1,2}$ and Penelope Hawe $e^{1,2,6}$

\begin{abstract}
Background: Chronic, non-communicable diseases are a significant public health priority, requiring action at individual, community and population levels, and public and political will for such action. Exposure to media, including news, entertainment, and advertising media, is likely to influence both individual behaviours, and attitudes towards preventive actions at the population level. In recent years there has been a proliferation of research exploring how chronic diseases and their risk factors are portrayed across various forms of media. This scoping review aims to map the literature in this area to identify key themes, gaps, and opportunities for future research in this area.

Methods: We searched three databases (Medline, PsycINFO and Global Health) in July 2016 and identified 499 original research articles meeting inclusion criteria: original research article, published in English, focusing on media representations of chronic disease (including how issues are framed in media, impact or effect of media representations, and factors that influence media representations). We extracted key data from included articles and examined the health topics, media channels and methods of included studies, and synthesised key themes across studies.

Results: Our findings show that research on media portrayals of chronic disease increased substantially between 1985 and 2016. Smoking and nutrition were the most frequent health topics, and television and print were the most common forms of media examined, although, as expected, research on online and social media channels has increased in recent years. The majority of studies focused on the amount and type of media coverage, including how issues are framed, typically using content analysis approaches. In comparison, there was much less research on the influences on and consequences of media coverage related to chronic disease, suggesting an important direction for future work.
\end{abstract}

Conclusions: The results highlight key themes across media research of relevance to chronic disease. More indepth syntheses of studies within the identified themes will allow us to draw out the key patterns and learnings across the literature.

Keywords: Chronic Disease, Health Communication, Mass Media, Scoping Review

\section{Background}

Chronic, non-communicable diseases (hereafter 'chronic diseases') such as cancer, diabetes mellitus and cardiovascular disease, are a major contributor to the global burden of disease and are responsible for over 40 million deaths per year [1]. Despite increasing recognition of the urgent need to tackle chronic diseases [2] and growing evidence

\footnotetext{
* Correspondence: samantha.rowbotham@sydney.edu.au

'Menzies Centre for Health Policy, Sydney School of Public Health, University

of Sydney, Sydney, Australia

${ }^{2}$ The Australian Prevention Partnership Centre, Sydney, Australia

Full list of author information is available at the end of the article
}

on both the effectiveness and cost-effectiveness of prevention [3], significant progress has not yet been made.

Chronic diseases are a complex problem, with multifactorial causes that extend beyond individual behaviours and include the social, environmental and socioeconomic aspects of the environments in which people live, work and play [4]. Chronic disease prevention therefore requires coordinated, inter-sectoral efforts at the individual, community and population levels $[4,5]$. For example, addressing childhood obesity is likely to require a range of interventions, including restricting junk food advertising to children, teaching cookery skills to

(c) The Author(s). 2020 Open Access This article is distributed under the terms of the Creative Commons Attribution 4.0 International License (http://creativecommons.org/licenses/by/4.0/), which permits unrestricted use, distribution, and reproduction in any medium, provided you give appropriate credit to the original author(s) and the source, provide a link to the Creative Commons license, and indicate if changes were made. The Creative Commons Public Domain Dedication waiver (http://creativecommons.org/publicdomain/zero/1.0/) applies to the data made available in this article, unless otherwise stated. 
new parents, providing nutritional information on food labels, changing school canteen menus, improving pricing and availability of fresh food, and reformulating processed foods [6]. Garnering public and political support and momentum for such actions requires a shift away from thinking at the individual level to an appreciation of the social, environmental and cultural drivers for behaviour, and an understanding of the interrelated nature of chronic disease causes, risk factors and solutions.

The public is continually exposed to mass media, including news, entertainment and advertising media, through channels such as television, radio, movies, newspapers, magazines and the internet. Such exposure is likely to play a key role in shaping attitudes and behaviours of relevance to chronic disease prevention [7]. News media lies at the nexus of the public and policy agenda and news coverage of issues and events both shapes and reflects public and political opinion [8]. While print newspapers are considered to be something of a 'dying industry', online news media exposure continues to increase, with much of the population having direct access 24 hours a day, 7 days a week, from almost any location [9]. Thus, the news media continues to be a vital social institution and digital technologies have reshaped this industry in recent years. In particular, the emergence of an array of new actors, such as BuzzFeed, The Huffington Post and The Conversation, along with the growth of social media platforms and blogs, has resulted in significant changes in who and what constitutes the news media institution. Further, the ease of sharing content across social networks, as well as the so-called 'echo-chamber' effect, have changed the flow of information, including what gets amplified and how. Understanding how these shifts in the media landscape affect the public and political agenda setting process will therefore be of increasing importance going forward.

The study of news media communication occurs within a multidisciplinary paradigm with roots in sociology and political science, and draws heavily on framing theory, which concerns the "holistic study of media effects on individuals and audiences" (p. 423 )[10], focusing on four elements of the communication process: the sender, the receiver, the (informative) message and culture [10]. Framing theory posits that messages are packaged in particular ways to emphasize certain pieces of information and de-emphasise others [11,12], and particular framings will "promote a particular problem definition, causal interpretation, moral evaluation, and/or treatment recommendation" (p.53 )[11]. Research within this paradigm has revealed that the nature of information conveyed through the media, including what gets reported, the amount of coverage received and the way in which it is represented can have a powerful effect on knowledge, attitudes, and behaviours [12-18]. In addition to shaping societal attitudes towards issues, media coverage is a societal product in itself, such that issue framing is constrained by social structures, values and norms $[19,20]$. Thus understanding how issues are framed can provide insights into wider trends in society.

Other forms of media, including entertainment, commercial advertising, and social marketing are also likely to play a role in influencing public attitudes, opinions and behaviours of relevance to chronic disease. For example, commercial advertising through television commercials, online advertising campaigns, and point of sale advertising are used often to influence consumer behaviours that may increase the risk of chronic diseases, such as encouraging consumption of unhealthy foods or alcohol (e.g., [21-23]), and may also encourage the purchase of products or services that promote health, such as commercial weight loss programs or meal plans. Social marketing campaigns may employ mass media channels to encourage healthy behaviours, such as smoking cessation, responsible alcohol consumption, and cancer screening (see, for example [24] for a review of mass media campaigns to change health behaviour). Entertainment media, such as films, television shows and music videos may influence attitudes and behaviours of relevance to chronic disease for example by using plotlines that raise awareness of issues related to chronic disease, or model behaviours such as smoking and alcohol consumption [25].

In recent years there has been a proliferation of media research on issues of relevance to chronic disease (including disease risks, causes and solutions). While such a growth in research is promising both in terms of interest in this field and the potential for new and useful knowledge to emerge, the volume and breadth of evidence can be overwhelming for those who need to access the key messages from this research, such as policy makers and practitioners. In particular, both original research articles and reviews have tended to 'zoom in' on specific issues, such as how obesity is portrayed within news media (e.g. [26-29]) or the framing of arguments around smoking restrictions (e.g. [30-35]), and to date, no comprehensive synthesis or mapping of the area as a whole exists.

Within this paper we aim to provide an initial mapping of media research on topics of relevance to chronic disease. In particular, we explore the scope and nature of research on how issues related to chronic disease prevention have been portrayed across various forms of media in order to provide an overview of the key focus areas and highlight gaps and opportunities for future investigation. In doing so we seek to address the following research questions:

- What are the key trends in research on media coverage of chronic diseases? 
- How has research on media coverage of chronic diseases changed over time?

- What are the key gaps and opportunities for further research on media coverage of chronic diseases?

\section{Methods}

Aim

To map existing research examining mass media content of relevance to chronic disease.

\section{Design}

A scoping review was selected as it allows for rapid mapping of the key concepts underpinning a research area and the main sources and types of evidence available [36] and is most appropriate when endeavouring to: examine the extent, range, and nature of research activity; summarize and disseminate research findings; and/or identify gaps in the existing research [37]. The methodology for this scoping review was based on previous the framework outlined by Arksey and O'Malley [37] and ensuing recommendations made by Levac, Colquhoun and O'Brien [38]. For the purpose of this study, a scoping review is defined as a type of research synthesis that aims to "map the literature on a particular topic or research area and provide an opportunity to identify key concepts; gaps in the research; and types and sources of evidence to inform practice, policymaking, and research" (p.2 )[39]. The review included the following five key phases: (1) identifying the research question, (2) identifying relevant studies, (3) study selection, (4) data extraction, and (5) collating, summarizing, and reporting the results. The review was completed in accordance with the PRISMA-ScR checklist [40] and copy of the completed checklist can be found in Additional file 2 .

\section{Search strategy}

We searched three electronic databases: MEDLINE (1946-), PsycINFO (1967-), and Global Health (1973-) via OVID in July 2016, to identify studies published in English. As the purpose of this review was to provide an overview of media research of relevance to lifestylerelated chronic diseases (e.g. cardiovascular disease, cancer, and diabetes), and their risk factors (e.g. smoking, alcohol consumption, obesity, physical activity), search terms were constructed across three concepts: topics and issues related to chronic disease (including search terms related to chronic diseases, risk factors, and public health), types of media (including advertising, news, entertainment and social media), and content or framing (see Table 1). Search terms were piloted and refined prior to use, including consultation with experts and checking for capture of studies that the authors expected to be included.

\section{Study selection}

In line with the recommendations of Levac, Colquhoun and O'Brien [38] the criteria for study inclusion were refined through discussion amongst the research team in an iterative manner as the reviewers became more familiar with the research. Studies were included if they reported original research related to media representations of chronic disease, including how issues are framed, the impact or effects of media representations (e.g. on public opinion or behaviour), and factors that influence media representations. Chronic diseases were defined as noncommunicable conditions, for which there are a range of lifestyle-related risk factors, and included cardiovascular disease, cancer, and diabetes. Studies were included if they focused on any issues related to chronic disease, including prevalence, causes and risk factors (e.g. obesity, high blood pressure, diet, physical inactivity, alcohol, smoking, social/ economic inequality), and/or prevention (including policies and programs). Although mental health issues were not a key focus of our search, a number of articles related to mental health were captured within our search terms. These were included these as they represent an important group of chronic conditions for which media coverage is likely to impact on public and political attitudes towards prevention and treatment. Only original research articles were included; other types of publications, including systematic reviews, meta-analyses, letters, and guidelines were not included within this review. Due to the volume of results returned by the database searches, further searching of grey literature and hand searching of reference lists and journals was beyond the scope of the study.

We included published articles that focused on any form of public media, including news media (e.g. newspapers, magazines, TV news), social media (e.g. Twitter, Facebook, blogs), entertainment media (e.g. TV sitcoms, movies, music videos), and/or advertising and marketing (including commercial advertisements and social marketing) (see Table 2 for definitions of media types). Conference abstracts, dissertations and other unpublished materials were not included within the review.

One reviewer (SR) screened article titles and abstracts for eligibility and reviewed the full-text of articles identified as 'eligible' or 'unclear'. For reliability purposes, a second reviewer (TAB) reviewed a random subset of articles on the basis of titles and abstracts $(n=100)$ and full-texts $(n=30)$. There was a good level of agreement at both stages (title and abstract: $86 \%$ agreement; Cohen's $k=.71$; full-text: $93 \%$ agreement; Cohen's $k=.84$ ) and all disagreements were discussed and resolved. Figure 1 outlines the flow of articles through the review process.

\section{Data extraction}

A data extraction template was developed in Microsoft Excel to extract key details about included studies. 
Table 1 Search strategy

\begin{tabular}{ll}
\hline Search terms & (Public Health/ OR Health promotion/ OR Health Education/ OR Health Policy/ OR Overweight/ OR \\
& Obesity/ OR Alcohol Drinking/ OR Binge Drinking/ OR Exercise/ OR Diet/ OR Food habits/ OR Smoking/ \\
& OR Smoking cessation/ OR Risk Factors/ OR Diabetes Mellitus, Type 2/ OR Hypertension/ OR Cardiovascular \\
& Diseases/ OR Chronic Disease/ OR Cancer) AND (Mass Media/ OR Communications Media/ OR Social \\
& Media/ OR television.mp OR radio.mp OR news*.mp OR media.mp OR Marketing/ or Marketing of health \\
& services/ or Social marketing/ OR advertis*.mp) AND (framing.mp OR frame.mp OR content analysis.mp) \\
Search limits & English language
\end{tabular}

Note: / denotes a MeSH heading; .mp denotes a free text search term

Extracted data included study characteristics, research focus, sample and methods, media types and topics covered. The data extraction form was initially reviewed by the research team and pretested by SR and TAB before use, and was continually refined during the early stages of data extraction. The characteristics of each full-text article were extracted by one reviewer (SR or TB), while a second reviewer (TAB or SR) performed data extraction on a randomly selected subset of full-text articles to check for consistency in information extracted. Comparison of extracted data indicated a high level of consistency and all disagreements were discussed and resolved.

\section{Data synthesis}

Extracted data were imported into NVivo qualitative data analysis software [41] for additional coding and data synthesis. Following the process outlined by Arksey and O'Malley [37], this began with a quantitative, descriptive analysis of the studies included within the review, including the distribution of studies over time, and media type and health topic in order to identify the dominant areas of research and any significant gaps. Following this a thematic approach [42] was employed, in which data were coded inductively to identify key themes in the focus areas and research questions of the included studies, attending to similarities and differences within and across the main media types in a way which accounted for the heterogeneity across studies. Data synthesis was performed by one reviewer (SR) and refined through ongoing discussion with the research team. Due to the volume of studies identified, a comprehensive synthesis of findings across all studies was beyond the scope of the current paper. Instead we have sought to categorise studies according to common themes and present examples of studies and key findings to highlight these.

\section{Results}

\section{Study characteristics}

Four hundred and ninety-nine studies were included in the review. Table 3 provides a description of the included studies and details of the key characteristics of each included study are also provided (see Additional File 1$)$. The majority of studies $(n=297 ; 60 \%)$ were conducted in the USA, followed by Australia $(n=52 ; 10 \%)$, Canada ( $n=37 ; 7 \%)$, and the United Kingdom $(n=31$; $6 \%$ ), and only $13(3 \%)$ studies took a multi-country approach (e.g. a comparative analysis of media coverage across countries). News and information media were the most frequent focus of studies followed by marketing media.

Studies were categorised according to the approach taken. Descriptive studies were those that involved an analysis (whether qualitative, quantitative or both) of media content, and were the most common study type within the sample $(n=446)$. Descriptive studies were most often cross-sectional in nature, i.e., the analysis of news coverage of a particular issue at a particular point in time, although some studies took a longitudinal approach, for example examining patterns in media coverage over time. A smaller number of studies $(n=60)$ employed an experimental approach, seeking to test the impact of differences in how chronic diseases were portrayed on a specified variable, e.g. testing the effect of presenting different framings of a news story on public attitudes to chronic disease, and included both lab-based and naturalistic studies.

Table 2 Definitions of media categories within this review

\begin{tabular}{ll}
\hline Media type & Definition \\
\hline News media & $\begin{array}{l}\text { Refers to any media that provides news or information, including print media (newspapers, magazines), } \\
\text { broadcast news (TV and radio news) and online news sites }\end{array}$ \\
Entertainment media & $\begin{array}{l}\text { Refers to non-news forms of entertainment, such as music, film, and television shows } \\
\text { Social media }\end{array}$ \\
Refers to websites and applications that allow users to create and share content or participate in social \\
networking (e.g. Facebook, Twitter, blogs) \\
Refers to media channels through which promotional messages are communicated to the public, \\
including both commercial and social marketing
\end{tabular}




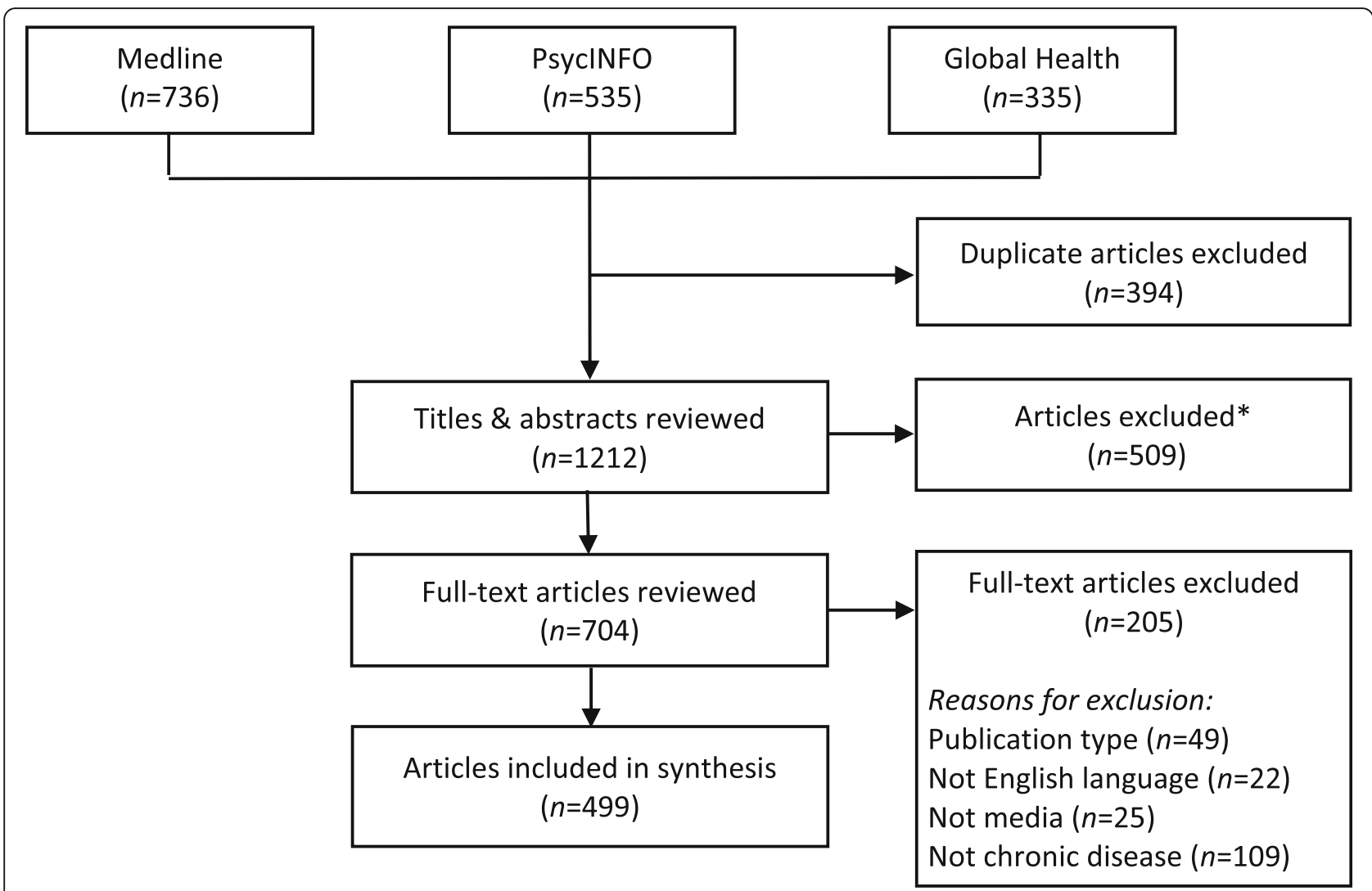

Fig. 1 Flow diagram depicting search strategy and review process. * Articles excluded at title and abstract screening stage did not meet inclusion criteria, such as studies of media framing of communicable diseases, studies that did not examine media content or framing, review and theoretical articles, and articles not published in English.

For studies of media content, the sample timeframe was most often between 0 and 5 years in duration, with a small proportion sampling over a duration exceeding 10 years. Newspapers were the most common media channel examined within our sample, followed by television and online media.

The number of studies increased over time. Studies covered a range of health topics related to chronic disease prevention, with the majority of studies $(n=342$; $69 \%$ ) focusing on behavioural risk factors related to chronic disease, particularly smoking and nutrition. Just over a quarter of studies $(n=134 ; 27 \%)$ focused on specific chronic diseases, including cancer $(n=93 ; 19 \%)$, type 2 diabetes $(n=15 ; 3 \%)$, cardiovascular disease $(n=16 ; 3 \%)$, and other chronic diseases (e.g. chronic kidney disease, hypertension; $n=9 ; 2 \%)$. Eighty-three studies (17\%) focused on other health topics relevant to chronic disease prevention, such as oral health, mental health, and child and maternal health. The cumulative frequency of studies for each health topic over time is displayed in Fig. 2.

\section{Synthesis of included studies}

Due to the volume of studies in our sample, for the purpose of synthesis we have grouped studies according to four broad media categories: 1) news media, 2) entertainment media, 3) social media, and 4) marketing media (see Table 2 for definitions of the media types used within this study). Mapping of the cumulative frequency of studies over time (see Fig. 3) revealed that news media has remained the most frequent focus of studies, followed by studies of marketing media (including both commercial marketing, e.g. of unhealthy products such as cigarettes, and social marketing, e.g. smoking cessation campaigns). However, in recent years, there has been an increase in the number of studies examining entertainment media such as television dramas, music and film, as well as an increase in studies of social media, such as Facebook and Twitter.

The distribution of health topics varied across the categories of media examined (see Fig. 4). While chronic diseases, obesity and other health topics were most frequently examined in the context of news media, nutrition was considered most often in relation to marketing media, and smoking, alcohol, and physical activity were considered at a similar rate in both news and marketing media.

\section{News media}

A total of 264 studies reported research on news media. Studies of news media included descriptive analyses of 
Table 3 Description of included studies

\begin{tabular}{|c|c|c|}
\hline Variable & $n^{\mathrm{a}}$ & $(\%)$ \\
\hline \multicolumn{3}{|l|}{ Continent } \\
\hline Africa & 4 & $(0.8)$ \\
\hline Asia $^{\mathrm{b}}$ & 31 & $(6.2)$ \\
\hline Australasia & 62 & $(12.4)$ \\
\hline Europe & 72 & (14.3) \\
\hline North America & 331 & $(66.3)$ \\
\hline Central or South America & 5 & $(1.0)$ \\
\hline \multicolumn{3}{|l|}{ Publication year } \\
\hline 1985-1989 & 1 & $(0.2)$ \\
\hline 1990-1994 & 9 & $(1.8)$ \\
\hline 1995-1999 & 20 & $(4.0)$ \\
\hline $2000-2004$ & 43 & (8.6) \\
\hline $2005-2009$ & 125 & $(25.0)$ \\
\hline $2010-2014$ & 207 & $(41.4)$ \\
\hline 2015-2016 & 94 & $(18.7)$ \\
\hline \multicolumn{3}{|l|}{ Media categories ${ }^{c}$} \\
\hline News & 264 & $(52.9)$ \\
\hline Entertainment & 45 & $(9.2)$ \\
\hline Social media & 49 & (9.8) \\
\hline Marketing & 159 & $(31.8)$ \\
\hline \multicolumn{3}{|l|}{ Methods } \\
\hline Descriptive & 446 & $(89.2)$ \\
\hline Experimental & 60 & $(12.0)$ \\
\hline Interview, survey or focus group & 46 & $(9.2)$ \\
\hline \multicolumn{3}{|l|}{ Media sample timeframe } \\
\hline Less than 1 year & 151 & $(30.1)$ \\
\hline $1-5$ years & 164 & $(32.7)$ \\
\hline $6-10$ years & 55 & $(11.0)$ \\
\hline $11-15$ years & 27 & $(5.4)$ \\
\hline More than 15 years & 35 & $(7.0)$ \\
\hline Not specified & 67 & $(13.4)$ \\
\hline \multicolumn{3}{|l|}{ Media channels } \\
\hline Television & 148 & $(29.7)$ \\
\hline Newspapers & 179 & $(35.7)$ \\
\hline Magazines & 87 & $(17.3)$ \\
\hline Radio & 9 & $(1.8)$ \\
\hline Movies & 12 & $(2.4)$ \\
\hline Music & 6 & $(1.2)$ \\
\hline Online (incl. online news, web pages and social media) & 93 & (18.6) \\
\hline $\begin{array}{l}\text { Other (incl. billboards, product packaging, constructed } \\
\text { messages) }\end{array}$ & 53 & $(10.6)$ \\
\hline Total Articles & 499 & \\
\hline
\end{tabular}

${ }^{a}$ Due to some articles being coded more than once within a category, the total within each category may exceed 499

${ }^{\mathrm{b}}$ Includes 1 study from Turkey

c See Table 2 for definitions of each of the media categories news content, studies of audience exposure to news, and investigation of factors that influence news reporting. Figure 5 provides an overview of the main themes and sub-themes of research within the news media category, and these are summarised in more detail below, along with example studies to illustrate.

\section{Content of news media}

A large proportion of studies $(n=244)$ focused on the content of news media, particularly in terms of the amount and/or type of news coverage of health issues $(n=207)$, and the characteristics of such coverage $(n=191)$. The majority of studies used content analysis approaches (e.g. [43-46]), with a smaller proportion of studies using other qualitative approaches, such as discourse analysis, to explore the patterns and trends in news media coverage (e.g. $[47,48]$ ).

Of those studies examining the amount and/or type of news coverage, a key focus was on news coverage over time $(n=71)$, particularly in terms of changes in the amount of coverage received and key themes within the coverage (e.g. [26, 28, 29, 32, 48-67]). For example, studies have found that the amount of news coverage of obesity [28, 29], cancer [58, 59], and smoking-related harms $[32,60]$ have increased over time. Other studies examined how the nature of news coverage had changed over time, for example demonstrating temporal changes in predominant themes and framing of tobacco [61, 62], alcohol use [53, 63, 64], obesity [28, 29, 65, 66], social and racial disparities in health [68], and mental health issues [67]. Other studies have used critical analysis methods to track how issues such as second handsmoke have emerged over time [48].

Another focus area was the impact of events or actions (e.g. implementation of interventions and policies) on news coverage $(n=15$; e.g. $[34,69-75])$. For example, one study considered how the framing of obesity shifted over the course of a sugar-sweetened beverage reduction media campaign [75], while another considered how news coverage of skin cancer changed following the release of a key public health report on cancer [70].

Nineteen studies compared the amount of news coverage received by different health topics (e.g. [68, 76-86]) and/or whether the amount of news coverage received was proportionate to the burden of the problem (e.g. [79, 87-92]). For example, two studies demonstrated that news coverage of a range of cancers is underrepresented relative to their population burden [89, 92]. Finally, studies have also considered how coverage differs across news media, including differences across news media aimed at different cultural or language groups (e.g. [93-98]), geographical regions (e.g. [99]), and news media types, such as middle market versus quality newspapers (e.g. [81]).

Studies focusing on characteristics of news coverage predominantly considered the framing of issues related 


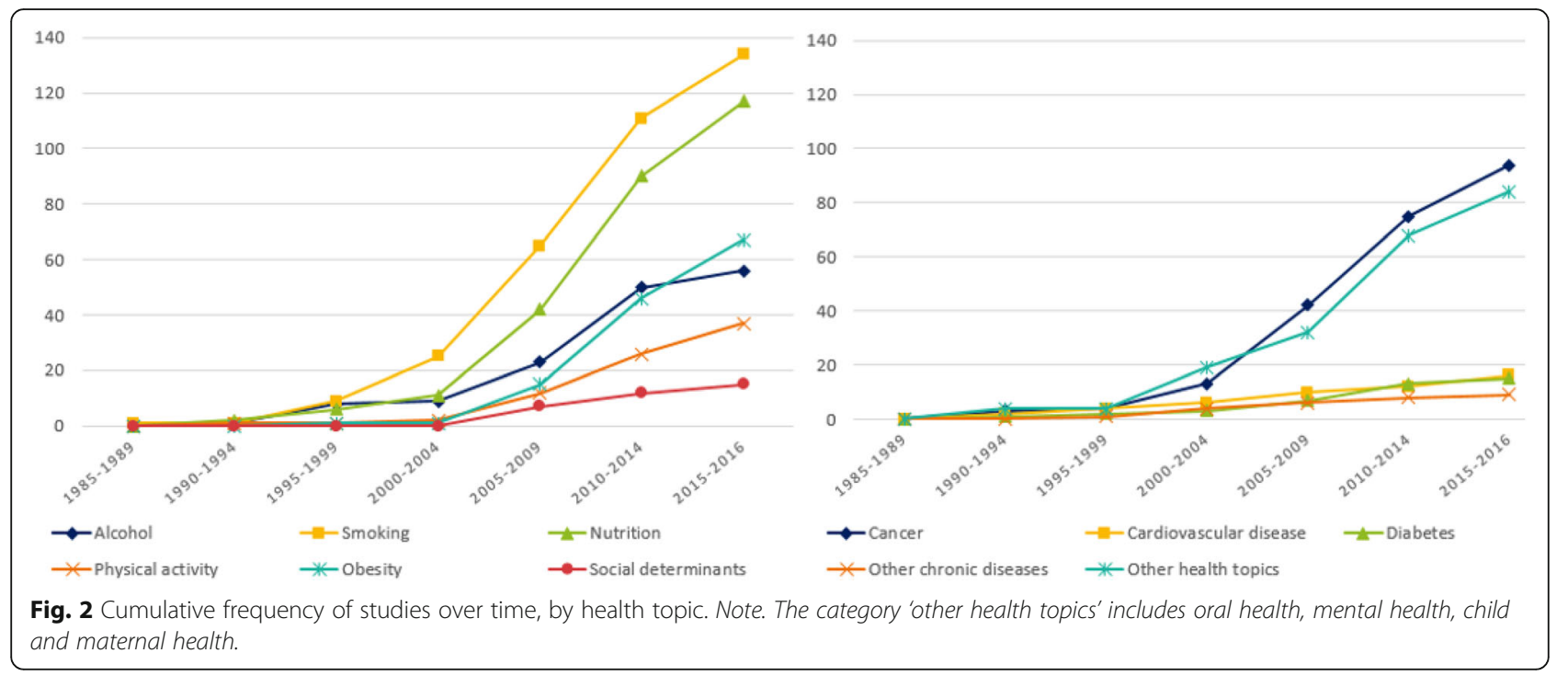

to chronic disease prevention $(n=147)$. The synthesis revealed that the most frequent focus was on valence of coverage (i.e. whether issues were framed positively or negatively) (e.g. [94, 99-109]), and responsibility for causes and solutions (e.g. individual versus government or industry responsibility) (e.g. [31, 61, 110-119]), with studies focusing on obesity being particularly prevalent here (e.g. [26, 27, 66, 75, 120-123]). Studies of valence and framing included those examining news coverage of particular behaviours of relevance to chronic disease, such as breastfeeding [94] and smoking [100], as well as those examining support for policy actions, such as regulation to limit sales of sugar sweetened beverages [102], an 'alcopop tax' on ready-to-drink spirits in Australia [103], and legislation for plain packaging of tobacco [124]. Examples of other specific types of frames studied included gain versus loss frames (e.g. $[125,126])$, thematic (which focus on the broader context) versus episodic frames (which focus on the immediate event or incident and give little or no context) (e.g. [29, 75, 82, 127]) and health versus appearance frames (e.g. [128]).

Twenty-six studies considered the quality of news media content, including how well content aligned with guidelines or recommendations (e.g. [94, 129-136]). For example, one study examined the accuracy of information and level of stigmatisation around obesity in newspaper articles [61], while another [137] considered the relationship between the amount of news coverage of food groups compared with the recommended amount of consumption of these foods. Finally, a number of

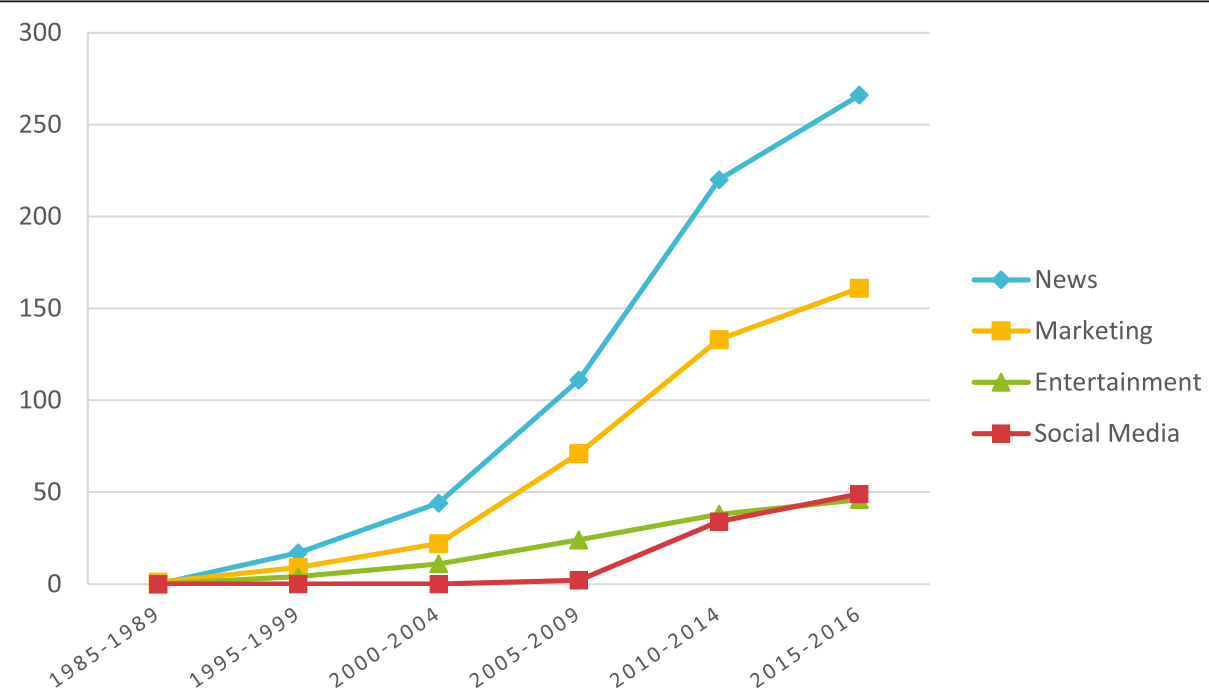

Fig. 3 Cumulative frequency of studies over time, by media type. Note. See Table 1 for definitions of media types used 


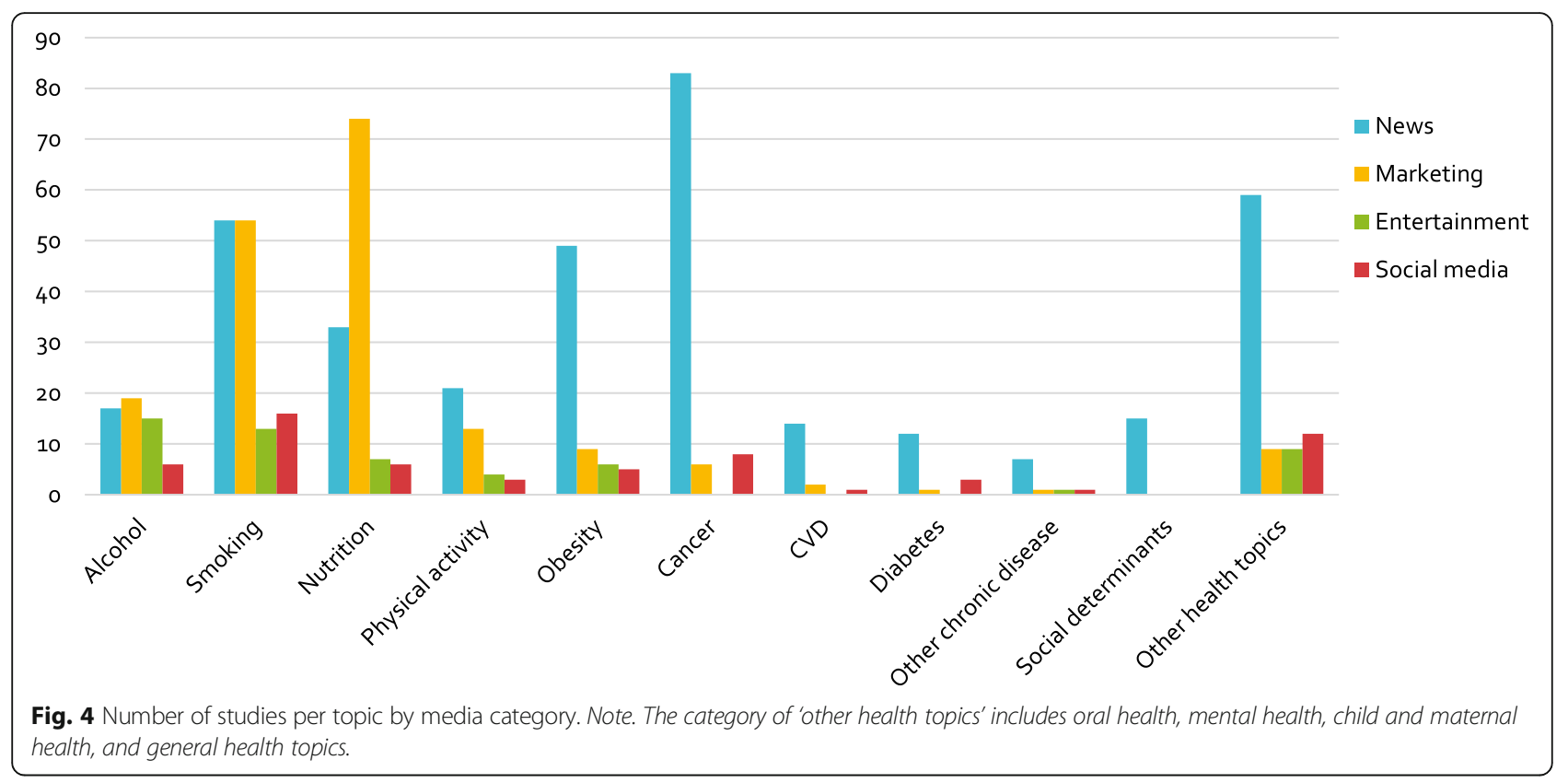

studies also considered structural characteristics of news media, including the prominence of articles and use of images (e.g. [71, 112, 138, 139]), while others considered the actors, evidence or sources used within news articles (e.g. $[80,119,140-144])$.

\section{Factors that influence news reporting}

Five studies examined factors that influence health reporting in the news media. Two used surveys to examine associations between journalist characteristics such as gender, age, ethnicity and experience, and news story characteristics, such as framing, source utilisation, and news priorities [145, 146]. A third study explored how journalists judge the newsworthiness of stories that report race-specific health disparities and whether informing journalists of audience reactions to different kinds of framing influences these judgements [147]. The remaining two used interviews to explore the barriers faced by journalists when covering health disparities in the media [148], and to seek the opinions of health experts on the problems of dominant obesity-prevention frames (personal responsibility and the environment) and explore alternative frames [149].

\section{Exposure to news media}

Of the 39 studies examining audience exposure to news media, eight focused on awareness of and/or attitudes towards news media, including investigations of public awareness of news coverage of chronic disease topics and health promotion campaigns (e.g. [150-152]), attitudes towards news coverage of issues such as obesity [153], factors that drive audience interest in prevention [154], and sociodemographic influences on exposure to news media [155].
A number of studies considered the effects of exposure to news media on or association with actual or intended behaviours (n=9; e.g. [136, 156-162]), or on knowledge, attitudes, and beliefs about the causes, consequences and solutions to a range of health issues $(n=25$, e.g. [49, $88,120,147,159,160,163-174])$. Such studies often employed experimental designs to test the impact of differences in framing (e.g. negative versus positive, thematic versus episodic, and gain versus loss frames), evidence use, and message salience (e.g. $[159,160,168$, $170,171,175])$. For example, one study found that participants who read a news article in which obesity was framed in societal (i.e. highlighting the role of the environment), rather than individual terms, were more likely to attribute obesity to social conditions and identify the government, food industry, and marketing sector to be responsible for solving the problem [160]. Other studies examined the relationship between community level news exposure and individual attitudes and behaviours using a combination of content analysis, surveys, interviews, and community-level health data (e.g. [88, 152, 161, 162]). For example using content analysis of local news media coverage of tobacco and community survey data, Smith and colleagues [162] found an association between volume of tobacco related newspaper articles and perceived harms of smoking, perceived peer smoking, disapproval of smoking, and smoking within the past 30 days.

Eight studies considered the impact of news exposure on attitudes towards public policies to tackle chronic disease [120, 168-170, 172, 173, 176, 177]. For example, one study found that thematic framing (i.e. incorporating information on context, risk factors, prevention 


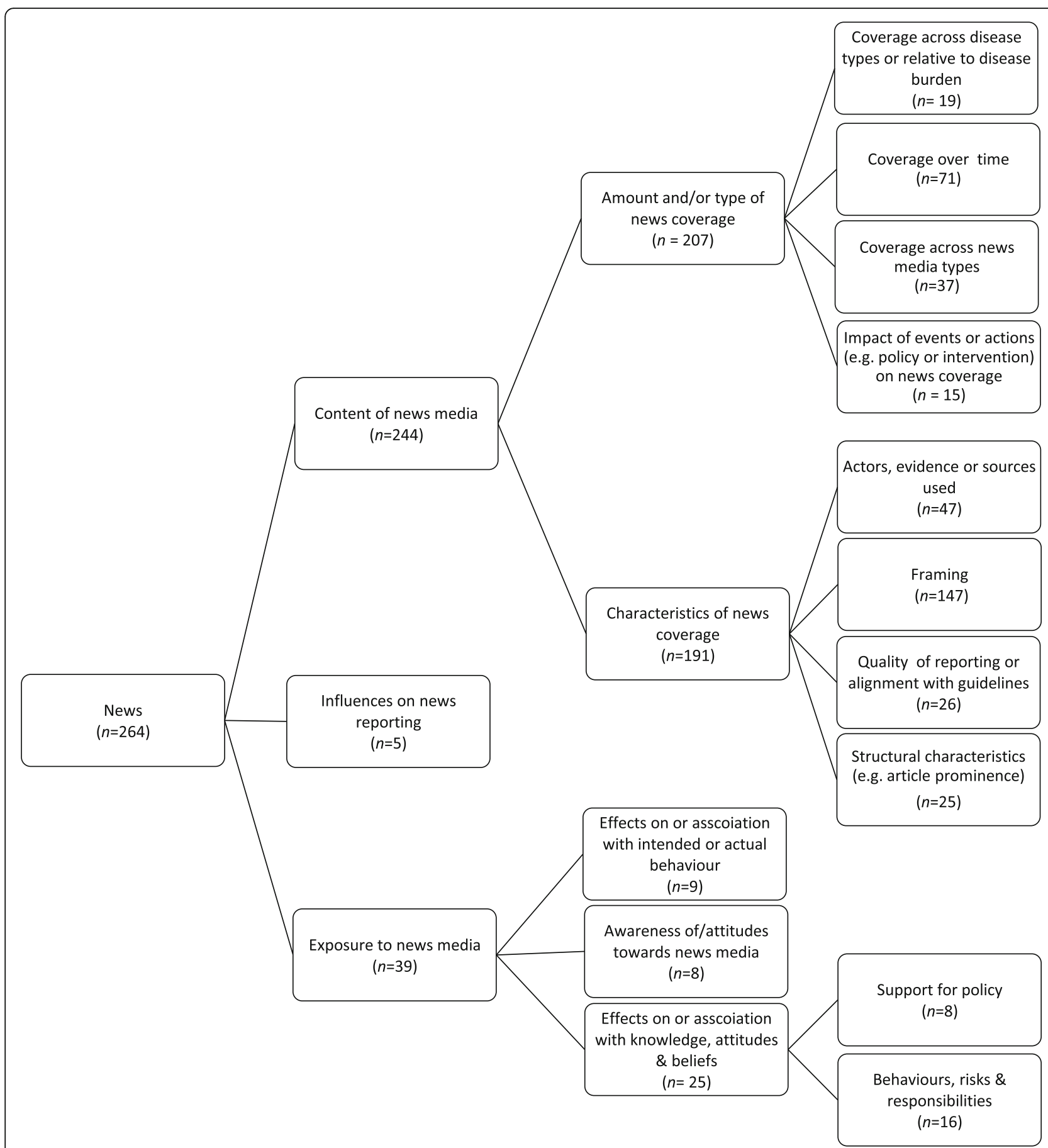

Fig. 5 Key themes across news media articles, including number of articles per theme. Note. Theme groupings are not mutually exclusive and articles are often coded to multiple themes.

strategies, and social attributions of responsibility), increases support for policy change across a range of health issues, including obesity, smoking and diabetes [168], while another found that a taste-engineering frame (i.e. highlighting strategies used by the food industry to increase consumption), increases support for food and beverage policies [172]. In contrast, individualising the problem of obesity by identifying an individual child within a news story was associated with reduced support for obesity policies, regardless of how causes of obesity were framed [120]. Finally, a study in the US demonstrated that the effect of framing on policy support is mediated by political opinion, with Democrats expressing a higher level of support for a range of public health 
policies after exposure to a social determinants of health frame, while Republicans expressed a lower level of support following exposure to the same message [170].

\section{Entertainment media}

Forty-five studies examined entertainment media, with most focusing on televised entertainment (including reality shows, drama, soaps and documentaries). The majority of studies involved descriptive analyses of entertainment media, and/or investigations into the effects of exposure to entertainment media. Figure 6 provides an overview of the main themes within this media category.

\section{Content of entertainment media}

Thirty-four studies considered the amount of coverage received by health topics (e.g. chronic disease prevention [178, 179];), products (e.g. alcohol, cigarettes, unhealthy food [180-182];) and behaviours (e.g. eating, drinking, smoking, weight stigmatization [183-191];) within entertainment media. One study considered the impact of regulation on the frequency of tobacco placement in movies [192].

Over half of the studies a considered the characteristics of coverage in entertainment media $(n=23)$, for example whether behaviour is portrayed in positive or negative terms (e.g. [180, 188, 193]), or using message appeal strategies such as sexualisation, glamour or humour (e.g. [182, $185,194])$. For example, one study found that depictions of alcohol in popular music were associated with wealth, sex, and luxury [194]. Four studies considered whether portrayals of food and drinks within entertainment media aligned with health recommendations, finding that they often do not [187, 195-197]. Nine studies examined the attributes of the characters involved in entertainment media representations, for example in terms of gender, ethnicity, and age (e.g. [186, 198]).

\section{Exposure to entertainment media}

Of the nine studies that considered exposure to entertainment media, the main focus areas were audience awareness of the issues portrayed through entertainment media ( $n=3$; e.g. $[152,193,199])$, audience attitudes towards portrayal of these issues $(n=5$; e.g. $[152,193,200$, 201]), and the effects of exposure to entertainment media on attitudes and behaviours ( $n=6$; e.g. [201-203]) For example, one study explored audience awareness of and attitudes towards an online social marketing campaign coupled with a popular TV series which aimed to reduce harmful alcohol consumption [193], while another examined the impact of alcohol portrayals in a television soap on adolescents' attitudes towards alcohol [202].

\section{Social media}

Forty-nine studies examined social media channels including Twitter and YouTube, social networking sites such as
Facebook and MySpace, blogs, and online discussion boards. Studies of social media primarily examined the content of social media $(n=48)$ and/or factors related to social media exposure $(n=14)$, including levels of social media engagement and the effects of exposure to messages via social media. Figure 7 provides an overview of the main themes of research within this media category.

\section{Analysis of social media content}

Of the 48 studies that examined the content of social media messages, 28 focused on the amount of coverage of issues related to chronic disease, and included studies of the number of tweets, blog posts or online comments about a particular issue or topic (e.g. smoking regulation, e-cigarettes, or alcohol use) (e.g. [204-211]). For example, one study examined the number of tweets related to hookah smoking [212], while another examined the frequency of health-related tweets by health professionals on Twitter [211].

Thirty-five studies examined characteristics of social media content. These included considerations of how issues such as smoking, alcohol use, cancer and eating disorders are depicted, for example in terms of the key themes in coverage of health topics (e.g. [207, 212-215]), the use of message appeal strategies and images (e.g. [216-220]), and studies of the quality of information conveyed through social media, including whether the information aligned with health recommendations (e.g. [210, $221,222]$ ). For example one study examined how responsibility and solutions for obesity are framed within YouTube videos [215]. Other studies considered how users talk about issues on social media (e.g. [223-226]), including the valence of messages, including public sentiment towards policy and regulation (e.g. [124, 227, 228]) and health promotion campaigns (e.g. $[193,229])$.

\section{Exposure to social media}

There were three main sub-themes identified within studies of exposure to social media coverage. The first examined audience awareness of or attitudes towards social media coverage of issues related to chronic disease (e.g. [221, 229-232]). For example, one study used focus groups and surveys to explore women's attitudes towards healthy eating blogs and their beliefs and attitudes towards using such blogs to improve their dietary habits [230], while another examined how friends react to adolescents' portrayals of alcohol on Facebook [232]. The second sub-theme contained studies that examined the factors associated with exposure to and/or engagement with social media coverage of issues related to chronic disease (e.g. [207, 232-234]). These included a study of the demographic factors associated with display of alcohol references on MySpace [207], and another examining whether exposure to tobacco content online was 


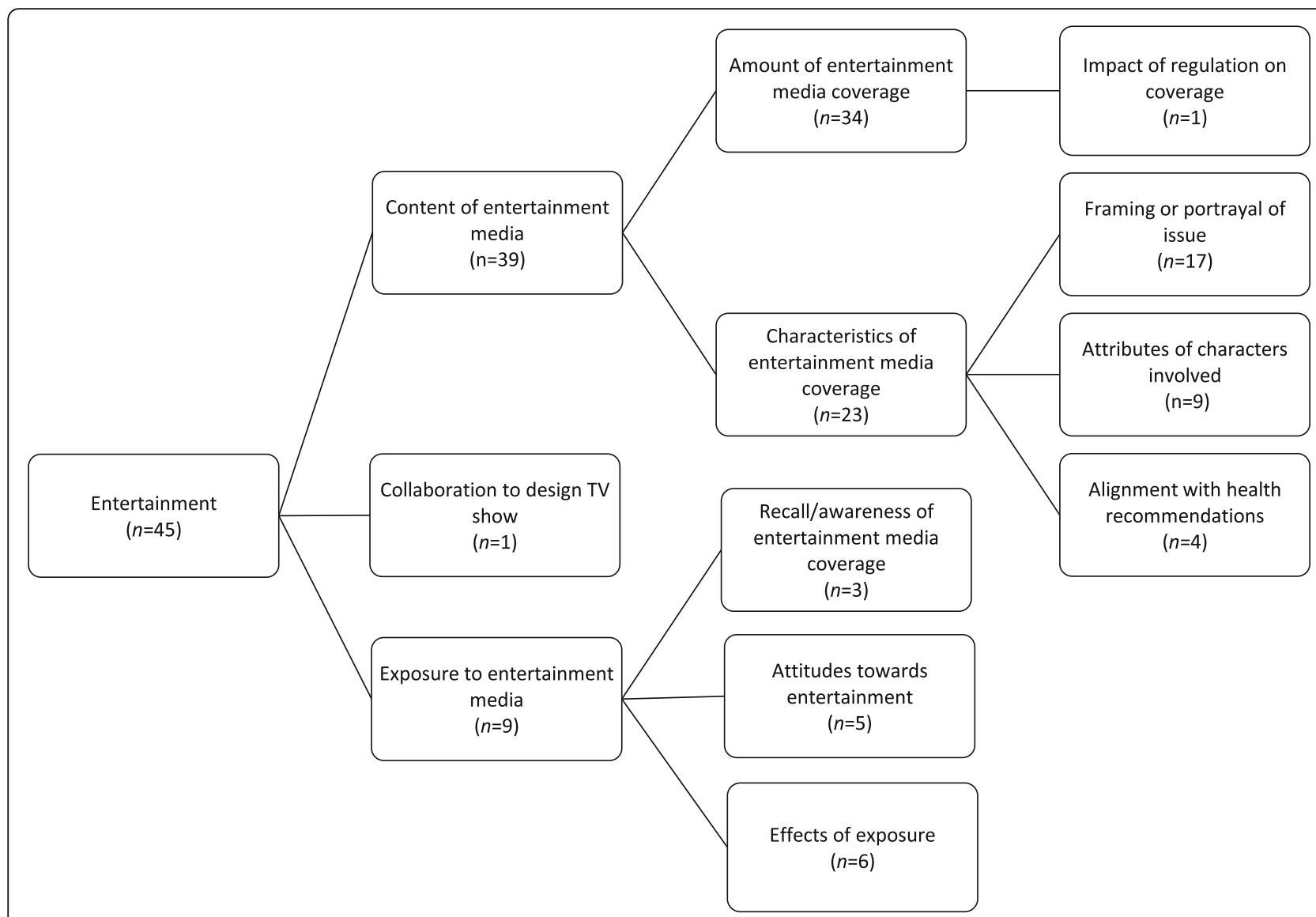

Fig. 6 Key themes across entertainment media articles, including number of articles per theme. Note. Theme groupings are not mutually exclusive and articles are often coded to multiple themes.

associated with smoking status [234]. Finally, one study examined the effect of exposure to social media messages on behaviour [235].

\section{Marketing media}

Overall, 159 studies focused on marketing media, of which the majority concerned commercial marketing $(n=110)$, with a smaller proportion concerning social marketing (e.g. health promotion campaigns) $(n=58)$. Figure 8 provides an overview of the main themes within this media category.

\section{Commercial marketing}

Of the 109 studies focused on commercial marketing media, the majority $(n=107)$ focused on examining product portrayals within commercial advertisements and product packaging, including frequency of advertisements and content and characteristics of marketing strategies (e.g. [236-268]), with the majority of studies focusing on tobacco and food advertising. For example, one study explored cigarette marketing strategies in India by examining cigarette advertising on billboards, storefronts and at point of sale as well as in films, magazines and newspapers [238], while another examined how tobacco companies increase magazine advertising in January and February to pre-empt quitting by providing cues to smoking [239]. Other studies examined how marketing strategies such as physical activity references (e.g. [241, 242, 269]), personal attributes (e.g. [270]), emotional appeals (e.g. [252]), and sexual imagery (e.g. [271]) were used to market products.

Nearly a quarter of studies $(n=21)$ focused on marketing regulations, with the majority of these considering the impact of regulation on advertising practices (e.g. [255, 271-278]). For example, one study evaluated the impact of industry self-regulation on television marketing of food to children [276], while another examined adherence to federal and voluntary standards for alcohol advertising in magazines [271]. Both studies found that while advertising regulations resulted in fewer advertisements, industries find ways to circumnavigate such restrictions [271, 276]. Other studies examined industry counter-strategies in response to advertising regulation, such as the use of brand imagery to promote tobacco use in the face of advertising restrictions (e.g. [277, 278]). 


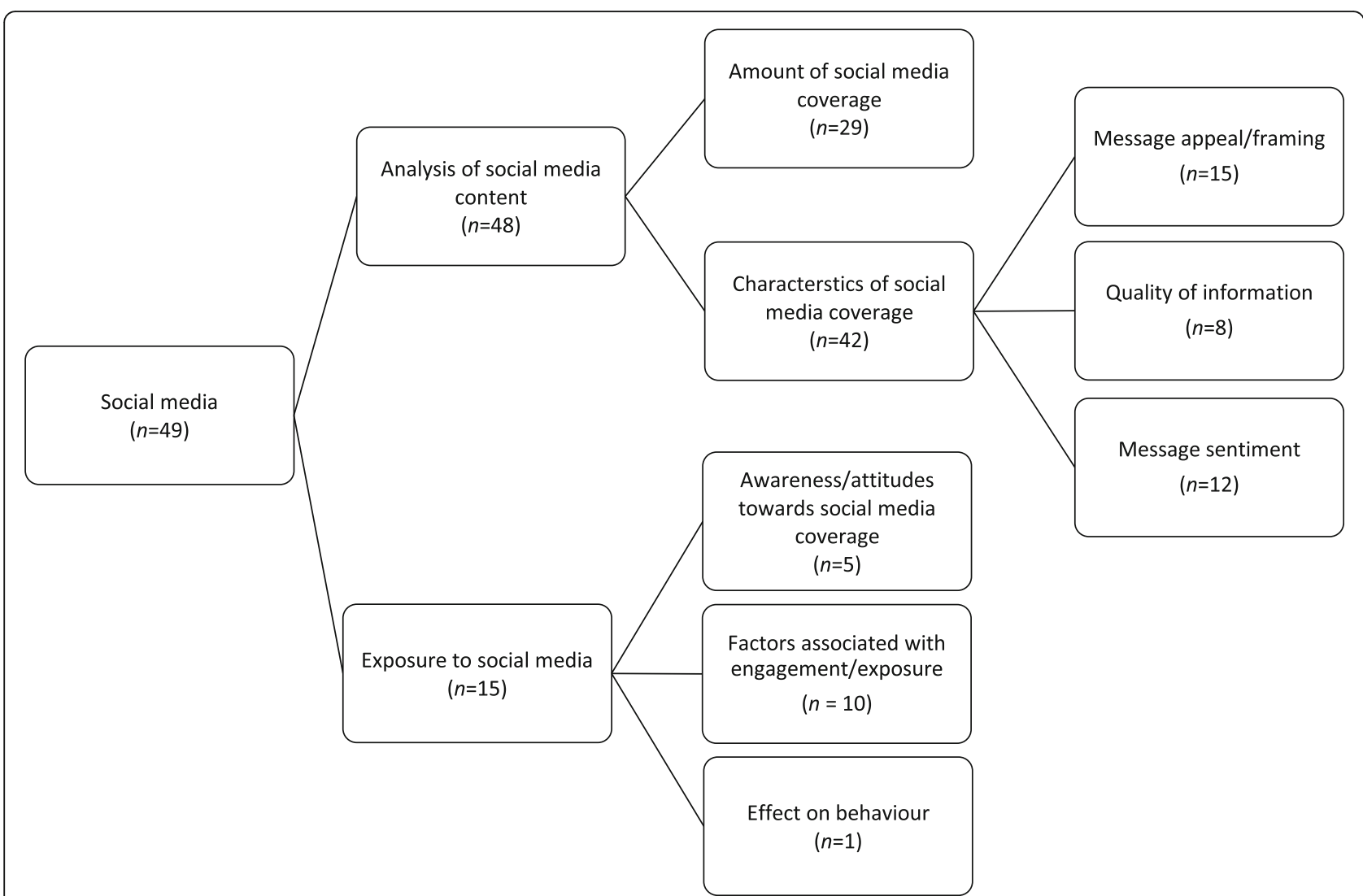

Fig. 7 Key themes across social media articles, including number of articles per theme. Note. Theme groupings are not mutually exclusive and articles are often coded to multiple themes.

\section{Social marketing}

Fifty-eight studies explored social marketing for health promotion. Of these, 34 involved an analysis of the content and characteristics of social marketing media, such as content analysis of the characteristics of antismoking or physical advertisements [269, 279]. Other studies explored the impact of social marketing strategies on consumer's attitudes and behaviours, for example using experimental approaches to examine the impact of message framing (e.g. gain- versus loss-framing) on healthrelated attitudes and behaviours such as seeking smoking cessation support [280], visiting the dentist [281], healthy snack choice [282], and chronic disease risk perception [283]. Eleven studies used focus groups, interviews and/or surveys to explore public perceptions of social marketing strategies (e.g., awareness, recall, liking, and perceived effectiveness of health promotion campaigns) [76, 284-286].

\section{Discussion}

We aimed to explore the scope and nature of research on media coverage of issues related to chronic disease. Research in this area has proliferated over the last three decades, with a particularly steep increase in the number of studies published since 2000. Across the sample, behavioural risk factors for chronic disease, tobacco smoking and nutrition especially, have received the most research attention. The volume of research on media portrayals of nutrition appears to be driven by research on advertising media, where there has been considerable focus on how unhealthy foods are marketed, particularly to children. In contrast, the volume of articles related to smoking seems to be driven by a combination of studies of cigarette marketing and news media representations of smoking. The large proportion of research articles examining media portrayals of smoking is unsurprising when considered in light of the huge shifts in public and political opinion in relation to tobacco control legislation, policy, and program support in recent decades. For example, since the 1970s in Australia, tobacco control advocacy, which is often enacted through news and other media coverage, has resulted in significant gains including advertising bans, increased taxation and banning of smoking in indoor spaces [287]. Much of the pioneering work in media advocacy and framing of public health issues therefore originated in tobacco control, and has paved the way for research into media portrayals of other public health issues [255, 288]. 


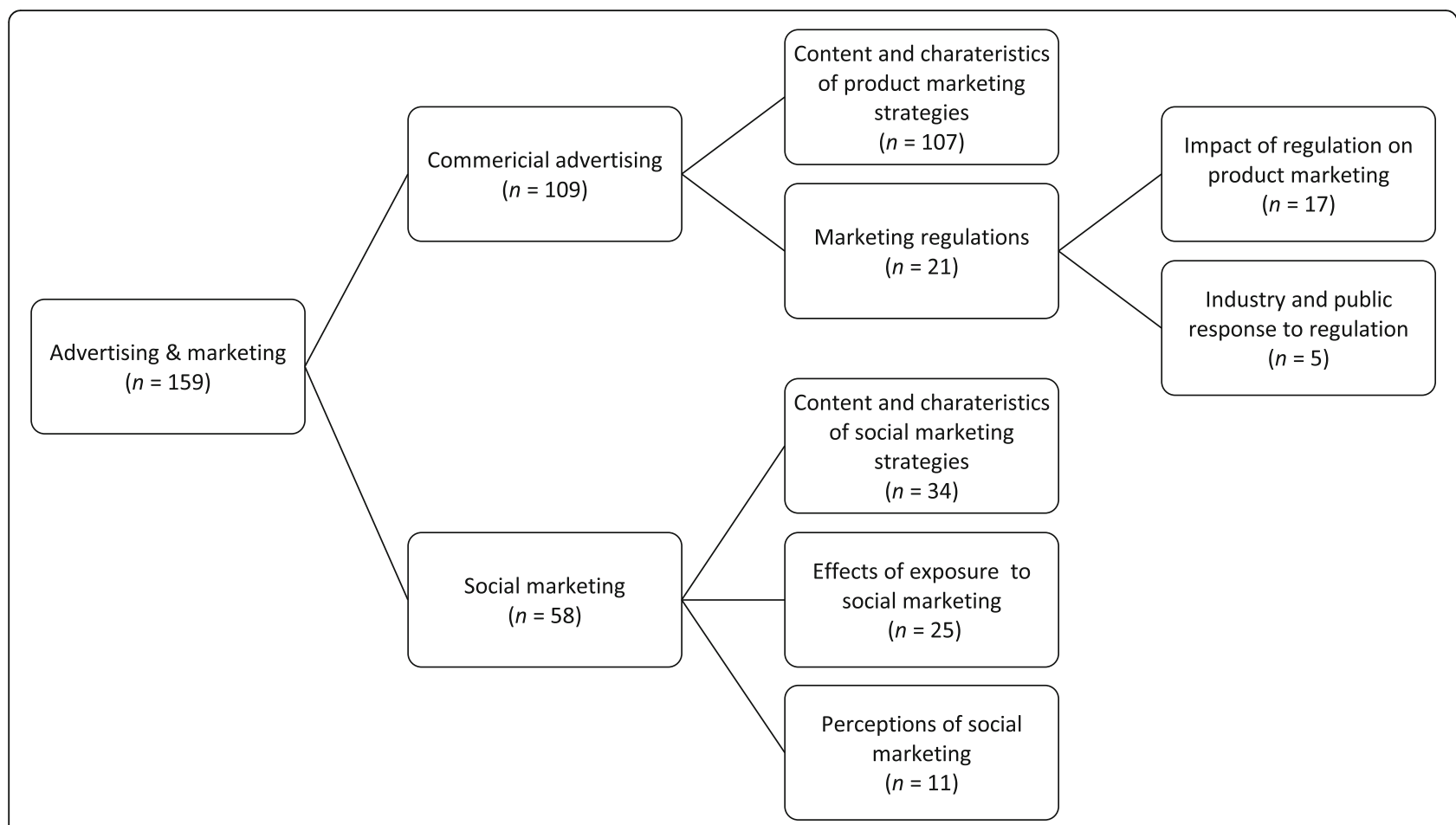

Fig. 8 Key themes across commercial advertising and social marketing media articles, including number of articles per theme. Note. Theme groupings are not mutually exclusive and articles are often coded to multiple themes.

The findings revealed a tendency for studies to focus on single health topics, with those studies that did consider multiple health topics tending to either examine closely related topics, such as nutrition and obesity, or focus on the amount of coverage across different topics $[91,183]$. Comparative analyses, such as those considering similarities and differences in media coverage of policies to encourage different health behaviours, such as smoking cessation and weight control [289] or considering the differential effects of framing effects on audience attitudes depending on health topic [168] were few and far between. In addition, there was only a handful of multi-country studies, for example, exploring how obesity was framed within news media in France and the US [290], and the impact of policies around online marketing of food to children across three countries [291]. Comparative approaches across countries and settings allow for exploration of the various contextual and cultural factors that influence media portrayal of issues related to chronic disease prevention, and allow broader insights and generalisations to be drawn. While such approaches may be challenging to undertake (not least when there are language differences to take into account), cross-country policy approaches to chronic disease prevention, such as those within the European Union or driven by the World Health Organisation require cross-country understanding of the media landscape.
The majority of studies in this review have focused on analyses of the content of media, with a large proportion of studies in each media category considering the content and characteristics of media coverage of a variety of issues (news $=92 \%$, entertainment $=85 \%$, social media $=98 \%$, marketing $=88 \%$ ). In contrast, a much smaller proportion of studies in each media category were concerned with the impact of exposure to media (news $=15 \%$, entertainment $=20 \%$, social media $=31 \%$, marketing $=16 \%$ ). This difference may reflect the relative ease of describing and analysing media content compared with assessing the impact of exposure to content on factors such as audience attitudes and behaviours. However, while studies of media content are valuable in demonstrating what issues are likely to gain traction within the media and provide important insights into the way that issues are being communicated to the public, it is also critical to understand the impact that such communications have on audiences' attitudes and behaviours. The effects of message framing on audiences cannot be taken for granted as audiences are not passive receptacles for information. Instead individuals actively engage with messages to a greater or lesser extent, and may accept, reject or negotiate how they interpret information, particularly in light of their existing knowledge, attitudes, beliefs, biases and previous experiences [292]. Understanding the factors that influence message interpretation is crucial in thinking about audience segmentation and targeting, and the range of potential impacts that a single 
message could have on different groups and across contexts of contrasting social and physical geographies. A good example of this is a study of differences in Republican vs. Democrat voter attitudes towards policy following presentation of the same message [170]. However, studying the effects of exposure to media is challenging, particularly as the social nature of interpreting media messages is difficult to capture through experimental methods, and reactions studied under artificial settings may not provide insights that are generalisable to community-based settings [293, 294]. However, social media platforms may provide us with a natural laboratory in which these kinds of effects could be studied (see below for a discussion of this).

There were also very few studies that consider the factors that influence media reporting of issues related to chronic disease. News reporting can be shaped by personal and professional biases [295], and understanding these biases is vital if we are to move beyond simple description of news stories towards strategies to change the way that issues related to chronic disease are portrayed.

In terms of the types of media that have been studied, news and marketing media have been the most frequent focus of research across the time period, with comparatively fewer studies of social media, such as Twitter, Facebook and YouTube. This is likely to be a historical bias which reflects the relatively recent growth of social media and advances in techniques for the analysis of social media data. In recent years the media landscape has changed, and continues to change rapidly, as people increasingly use social media platforms to access news and entertainment media, as well as to interact with others [9]. An understanding of how issues related to chronic disease are being portrayed and discussed within these social media spaces will be crucial going forwards. In particular, social media platforms represent a more interactive form of media engagement that traditional channels such as newspapers and radio, allowing audiences to share and discuss information in real time, while algorithms such as those used by Facebook use a range of information to target the content that users are exposed to. Social media platforms therefore provide fertile ground for research examining the diffusion and reverberation of information within and across networks, audience discussion and opinions about a range of issues, and provide opportunities for experiments to test how audience react to and interact with different kinds of messages related to chronic disease. There is already pioneering work happening within this space, and we would expect to see a rapid growth in research in these areas in the coming years.

\section{Limitations}

Within this scoping review we have provided a snapshot of the current landscape of research on media portrayals of issues related to chronic disease, highlighting the key focus areas across the field as a whole, and thus going further than previous reviews which have tended to focus on media portrayals of single health topics or media types (e.g. [296, 297]). As a result, this review was necessarily broad and our search strategy reflects this, for example in the decision to use a select subset of key MESH headings to capture articles in each of the topic areas rather than an exhaustive list of key words. As pointed out by one of the reviewers of this article, this may have resulted in the omission of relevant papers that used different terms from those contained in our search strategy. For example, it was noted that the work by Emery and colleagues on Twitter content related to tobacco use [298, 299] was not picked up within our search. However, a post-hoc deployment of our search strategy in Medline with the inclusion of additional search terms related to the original search terms for 'smoking' (addition terms: Tobacco Smoking/ OR Tobacco/ OR Tobacco, Smokeless/ OR Electronic Nicotine Delivery Systems/ OR Tobacco Products/ OR Vaping/ OR e-cig*.mp OR cigarette.mp OR juul.mp) and 'social media' (additional terms: facebook.mp OR twitter.mp OR Instagram.mp OR youtube.mp) only returned an additional 26 and 9 articles respectively (prior to any screening to assess whether these additional studies met the inclusion criteria). Similarly, we recognise that the decision to use 'content analysis' as search term (see Table 1) may have resulted in the omission of studies using different approaches such as discourse or textual analysis. However, the use of 'frame' and 'framing' as alongside 'content analysis' (see Table 1) meant that articles that examined framing of chronic disease issues using approaches other than content analysis were still captured within our search. Indeed, a post-hoc re-run of our search strategy with the addition of 'discourse analysis' and 'text analysis' in Medline, only returned an additional 34 results prior to any screening. As such, while a minority of papers may indeed have been missed as a result of our search strategy, this review still serves as a useful and novel snapshot of the literature, as intended when we set out to undertake a scoping review, and the current search strategy is unlikely to have significantly biased the findings.

The breadth of this review, spanning media coverage of a range of non-communicable diseases and their risk factors, meant that there was an extremely high volume of search results returned and articles included, which had implications for our handling of the data. First, due to the volume of results returned from the databases searches, and the intention for this review to be a 'rapid mapping' of key themes in this area, we did not extend the search to include unpublished literature or handsearching of journals and recognise that this may have 
led to some studies being missed. Second, while it would have been desirable to have a second reviewer check all references for inclusion and data extraction, the volume of literature precluded this. Instead, we engaged in frequent discussions within the research team to ensure consistency and discuss uncertainties as they arose, and additional reviewers checked randomly selected subsets of data and demonstrated a high level of agreement (see 'Study selection'). Finally, while more applicable to systematic reviews than scoping reviews, the large number of studies included within our sample meant that critical appraisal of the evidence and assessment of study quality was beyond the scope of this review.

Finally, the volume of studies identified within this review also presented challenges to data synthesis. For example, while we have identified a number of studies examining media portrayals of different policy interventions such as smoking regulation and sugar taxes, a more in depth synthesis of these papers to draw out similarities and differences in how different policies are framed within the news media and how this influences public opinion will be a valuable next step. Another insight that would be important to follow up is how risks, causes and solutions of chronic diseases have been framed across the topic areas in order to identify similarities and differences and the impacts of different framings across topics.

\section{Conclusions}

This scoping review provides a high-level overview of the key topics, approaches and themes across existing research on media coverage of issues related to chronic disease spanning more than thirty years. Taken together, the findings of this review indicate that while there has been a considerable body of research on the amount and type of media coverage of issues related to chronic disease prevention, there has been less focus on the factors that influence the amount and type of media coverage, and the effects of media coverage on public attitudes and behaviours. While an understanding of how issues are framed within the news media is vital to understanding how stories around chronic disease are being told, greater understanding of the factors that influence how issues related to chronic disease prevention get reported and what audiences do with the information is needed going forwards. Further synthesis of study findings across different risk factors, causes and solutions, is also an important next step in order to demonstrate the key insights from the field as a whole that can be applied to aid understanding of future actions. For example, we recently conducted a synthesis of studies of the content and effects of media framing of a range of policy interventions for chronic disease prevention to inform an understanding of the how future policies might be portrayed in the media and responded to by the public [300]. Finally, while not the main focus of our search, we noted a steady increase in recent years in the number of articles considering the social determinants of health in relation to chronic disease prevention, which may represent an important shift towards recognising the key role that such factors play in shaping health.

\section{Supplementary information}

Supplementary information accompanies this paper at https://doi.org/10. 1186/s12889-020-8365-x.

Additional file 1. Characteristics of included papers.

Additional file 2. Preferred Reporting Items for Systematic reviews and Meta-Analyses extension for Scoping Reviews (PRISMA-ScR) Checklist.

\section{Acknowledgments}

We would like to thank Dr Becky Freeman for feedback at various stages throughout the process.

We dedicate this work to our colleague, mentor, and above-all friend, Associate Professor Sonia Wutzke (1970-2017). The public health community is richer for having had you as one of its most passionate advocates and our lives are richer for having had the privilege of knowing you.

\section{Authors' contributions}

SR and PH had the original idea for the review. The search strategy was developed by SR, in discussion with $\mathrm{PH}$ and TAB. The search, data extraction and synthesis was conducted primarily by SR in close collaboration with TAB and TB. The first draft of the paper was prepared by SR, with major contributions to further drafting from all authors. All authors read and approved the final manuscript.

\section{Funding}

The work was funded by the National Health and Medical Research Council of Australia (NHMRC) through its Partnership Centre grant scheme (grant GNT9100001). NSW Health, ACT Health, the Australian Government Department of Health, the Hospitals Contribution Fund of Australia and the HCF Research Foundation have contributed funds to support this work as part of the NHMRC Partnership Centre grant scheme. TAB was supported by a National Health and Medical Research Council Boosting Dementia Research Leader Fellowship (\#1140317). The funding partners did not have a role in any aspect of this research. The contents of this paper are solely the responsibility of the individual authors and do not reflect the views of the NHMRC or other funding partners.

\section{Availability of data and materials}

Not applicable

\section{Ethics approval and consent to participate} Not applicable

\section{Consent for publication}

Not applicable

\section{Competing interests}

The authors declare that they have no competing interests.

\section{Author details}

${ }^{1}$ Menzies Centre for Health Policy, Sydney School of Public Health, University of Sydney, Sydney, Australia. ${ }^{2}$ The Australian Prevention Partnership Centre, Sydney, Australia. ${ }^{3}$ Population Wellbeing and Environment Research Lab (PowerLab), School of Health and Society, University of Wollongong, Wollongong, Australia. ${ }^{4}$ School of Public Health, Peking Union Medical College and The Chinese Academy of Medical Sciences, Beijing, China. ${ }^{5}$ National Institute of Environmental Health, Chinese Center for Disease Control and Prevention (China CDC), Beijing, China. ${ }^{6} \mathrm{O}^{\prime}$ Brien Institute of Public Health, University of Calgary, Calgary, Canada. 
Received: 4 December 2018 Accepted: 17 February 2020 Published online: 20 March 2020

\section{References}

1. World Health Organization. Global health estimates 2016: deaths by cause, age, sex, by country and by region, 2000-2016. Geneva: World Health Organization; 2018.

2. Bloom D, Cafiero E, Jané-Llopis E, Abrahams-Gessel S, Bloom L, Fathima S, Feigl A, Gaziano T, Hamandi A, Mowafi M. The global economic burden of noncommunicable diseases: Program on the Global Demography of Aging; 2012.

3. Vos T, Carter R, Barendregt J, Mihalopoulos C, Veerman L, Magnus A, Cobiac L, Bertram M, Wallace A. Assessing Cost-Effectiveness in Prevention (ACEPrevention). Final Report: University of Queensland, Brisbane and Deakin University, Melbourne; 2010.

4. Willcox S. Chronic diseases in Australia: the case for changing course: background and policy paper. Melbourne: Australian Health Policy Collaboration; 2014.

5. World Health Organization. The Ottawa Charter for Health Promotion. Geneva: WHO; 1986

6. World Health Organization. Population-based prevention strategies for childhood obesity: report of a WHO forum and technical meeting. Geneva: World Health Organization; 2010.

7. Marteau TM, Hollands GJ, Fletcher PC. Changing human behavior to prevent disease: the importance of targeting automatic processes. Science. 2012;337:1492-5.

8. Akintola O, Lavis JN, Hoskins R. Print media coverage of primary healthcare and related research evidence in South Africa. Health Res Policy Syst. 2015; 13:68.

9. Deloitte. Media Consumer Survey 2016: Australian media and digital preferences Australia; 2016

10. Ardèvol-Abreu A. Framing theory in communication research. Origins, development and current situation in Spain. Rev Lat De Comunicación Soc. 2015:70:423-50.

11. Entman RM. Framing: toward clarification of a fractured paradigm. J Commun. 1993:43:51-8.

12. Tewksbury D, Scheufele DA. News framing theory and research. In: Media effects: Advances in Theory and Research. edn. Edited by Bryant J, Oliver MB. Hillsdale, NJ: Erlbaum; 2009: 17-33.

13. Bartels LM. Messages received: the political impact of media exposure. Am Polit Sci Rev. 1993;87:267-85.

14. lyengar S. Is anyone responsible? How television frames political issues: University of Chicago Press; 1991.

15. Anderson P, de Bruijn A, Angus K, Gordon R, Hastings G. Impact of alcoho advertising and media exposure on adolescent alcohol use: a systematic review of longitudinal studies. Alcohol Alcoholism. 2009;44:229-43.

16. Levendusky M. Partisan media exposure and attitudes toward the opposition. Polit Commun. 2013;30:565-81.

17. McCombs ME, Shaw DL. The agenda-setting function of mass media. Public Opin Quart. 1972;36:176-87.

18. Abroms LC, Maibach EW. The effectiveness of mass communication to change public behavior. Annu Rev Public Health. 2008;29:219-34.

19. Gentzkow M, Shapiro JM. What Drives Media Slant? Evidence From U.S. Daily Newspapers. What Drives Media Slant? Evidence From U.S. Daily Newspapers. 2010;78:35-71.

20. Reese SD, Gandy OH, Grant AE. Framing public life: perspectives on media and our understanding of the social world. Mahwah, N.J: Lawrence Erlbaum Associates; 2001.

21. Kelly B, Smith B, King L, Flood V, Bauman A. Television food advertising to children: the extent and nature of exposure. Public Health Nutr. 2007;10: 1234-40.

22. Boyland EJ, Halford JC. Television advertising and branding. Effects on eating behaviour and food preferences in children. Appetite. 2013;62:236-41.

23. Altman $\mathrm{DG}$, Slater MD, Albright $\mathrm{CL}$, Maccoby N. How an unhealthy product is sold: cigarette advertising in magazines, 1960-1985. J Commun. 1987;37: 95-106.

24. Wakefield MA, Loken B, Hornik RC. Use of mass media campaigns to change health behaviour. Lancet. 2010:376:1261-71.

25. Moyer-Gusé E. Toward a theory of entertainment persuasion: Explaining the persuasive effects of entertainment-education messages. Commun Theor. 2008;18:407-25
26. Barry $C L$, Jarlenski $M$, Grob R, Schlesinger M, Gollust SE. News media framing of childhood obesity in the United States from 2000 to 2009. Pediatrics. 2011;128:132-45.

27. Bonfiglioli CMF, Smith BJ, King LA, Chapman SF, Holding SJ. Choice and voice: obesity debates in television news. Med J Australia. 2007;187:442-5.

28. De Brun A, McKenzie K, McCarthy M, McGloin A. The emergence and portrayal of obesity in The Irish Times: content analysis of obesity coverage, 1997-2009. Health Commun. 2012;27:389-98.

29. Gearhart S, Craig C, Steed C. Network news coverage of obesity in two time periods: an analysis of issues, sources, and frames. Health Commun. 2012;27: 653-62.

30. Champion D, Chapman S. Framing pub smoking bans: an analysis of Australian print news media coverage, March 1996-March 2003. J Epidemiol Commun Health. 2005;59:679-84.

31. Freeman B, Chapman S, Storey P. Banning smoking in cars carrying children: an analytical history of a public health advocacy campaign. Aust NZ J Publ Heal. 2008:32:60-5.

32. Hilton S, Wood K, Bain J, Patterson C, Duffy S, Semple S. Newsprint coverage of smoking in cars carrying children: a case study of public and scientific opinion driving the policy debate. BMC Public Health. 2014;14:1116.

33. Lando HA, Michaud ME, Poston WSC, Jahnke SA, Williams L, Haddock CK. Banning cigarette smoking on US Navy submarines: a case study. Tob Control. 2015;24:e188-92.

34. Niederdeppe J, Farrelly MC, Wenter D. Media advocacy, tobacco control policy change and teen smoking in Florida. Tob Control. 2007;16:47-52

35. Patterson C, Semple S, Wood K, Duffy S, Hilton S. A quantitative content analysis of UK newsprint coverage of proposed legislation to prohibit smoking in private vehicles carrying children. BMC Public Health. 2015;15:760.

36. Mays N, Roberts E, Popay J. Synthesising research evidence. In: Studying the organisation and delivery of health services: Research methods. edn. Edited by Fulop N, Allen P, Clarke A, Black N. London: Routledge; 2001: 188-220.

37. Arksey H, O'Malley L. Scoping studies: towards a methodological framework. Int J Soc Res Method. 2005;8:19-32.

38. Levac D, Colquhoun $\mathrm{H}$, O'Brien KK. Scoping studies: advancing the methodology. Implement Sci. 2010;5:69.

39. Daudt HM, van Mossel C, Scott SJ. Enhancing the scoping study methodology: a large, inter-professional team's experience with Arksey and O'Malley's framework. BMC Med Res Methodol. 2013;13:48.

40. Tricco AC, Lillie E, Zarin W, O'Brien KK, Colquhoun H, Levac D, Moher D, Peters MD, Horsley T, Weeks L. PRISMA extension for scoping reviews (PRISMA-SCR): checklist and explanation. PRISMA extension for scoping reviews (PRISMA-SCR): checklist and explanation. 2018; 169: 467-473.

41. QSR International Pty Ltd. NVivo Pro Software. In., 11 edn; 2015.

42. Braun V, Clarke V. Using thematic analysis in psychology. Using thematic analysis in psychology. 2006; 3: 77-101.

43. Andsager JL, Chen L, Miles S, Smith CC, Nothwehr F. Nutrition information in community newspapers: goal framing, story origins, and topics. Health Commun. 2015;30:1013-21.

44. Wakefield MA, Brennan E, Durkin SJ, McLeod K, Smith KC. Still a burning issue: trends in the volume, content and population reach of newspaper coverage about tobacco issues. Crit Public Health. 2011;21:313-25.

45. Wenger $L$, Malone R, Bero L. The cigar revival and the popular press: a content analysis, 1987-1997. Am J Public Health. 2001;91:288-91.

46. Wood K, Patterson C, Katikireddi SV, Hilton S. Harms to 'others' from alcohol consumption in the minimum unit pricing policy debate: a qualitative content analysis of U.K. newspapers (2005-12). Addiction. 2014;109:578-84.

47. Mainland M, Shaw S, Prier A. Fearing fat: exploring the discursive links between childhood obesity, parenting, and leisure. J Leisure Res. 2015;47:202-19.

48. Bell K. Science, policy and the rise of 'thirdhand smoke' as a public health issue. Health Risk Soc. 2014;16:154-70.

49. Dixon H, Warne C, Scully M, Dobbinson S, Wakefield M. Agenda-setting effects of sun-related news coverage on public attitudes and beliefs about tanning and skin cancer. Health Commun. 2014;29:173-81.

50. Liu Y, Liu M, Xiao H, Cai J, Xu W. A content analysis of news coverage of skin cancer in China newspapers. Health Commun. 2010;25:647-9.

51. Potter B, Sheeshka J, Valaitis R. Content analysis of infant feeding messages in a Canadian women's magazine, 1945 to 1995. J Nutr Educ. 2000:32:196-203.

52. Al-Naggar RA, Al-Jashamy K. Breast cancer coverage in the media in malaysia: a qualitative content analysis of star newspaper articles. Asian Pac J Cancer P. 2011;12:3397-401. 
53. Azar D, White V, Bland S, Livingston M, Room R, Chikritzhs T, Durkin S, Gilmore W, Wakefield M. 'Something's brewing': the changing trends in alcohol coverage in Australian newspapers 2000-2011. Alcohol Alcoholism. 2014:49:336-42.

54. Barker ME, McNeir K, Sameer S, Russell J. Food, nutrition and slimming messages in British women's magazines, 1950-1998. J Hum Nutr Diet. 2014; 27(Suppl 2):124-34.

55. Cardador MT, Hazan AR, Glantz SA. Tobacco industry smokers' rights publications: a content analysis. Am J Public Health. 1995;85:1212-7.

56. Spencer RJ, Russell JM, Barker ME. Temporality in British young women's magazines: food, cooking and weight loss. Public Health Nutr. 2014;17: 2359-67.

57. Warsh CK, Tinkler P. In Vogue: North American and British representations of women smokers in Vogue, 1920s-1960s. Canadian Bulletin of Medical History. 2007; 24: 9-47.

58. Cai J, Yang L, Liu Z, Ma Z, Liu Y. Comprehensive analysis of cancer coverage in important Chinese newspapers between 2000 and 2007. Support Care Cancer. 2009;17:329-32.

59. Heneghan MK, Hazan C, Halpern AC, Oliveria SA. Skin cancer coverage in a national newspaper: a teachable moment. J Cancer Educ. 2007;22:99-104.

60. Kennedy GE, Bero LA. Print media coverage of research on passive smoking. Tob Control. 1999;8:254-60.

61. Mejia P, Dorfman L, Cheyne A, Nixon L, Friedman L, Gottlieb M, Daynard R. The origins of personal responsibility rhetoric in news coverage of the tobacco industry. Am J Public Health. 2014;104:1048-51.

62. Nelson DE, Pederson LL, Mowery P, Bailey S, Sevilimedu V, London J, Babb S, Pechacek T. Trends in US newspaper and television coverage of tobacco. Tob Control. 2015;24:94-9.

63. Hilton S, Wood K, Patterson C, Katikireddi SV. Implications for alcohol minimum unit pricing advocacy: what can we learn for public health from UK newsprint coverage of key claim-makers in the policy debate? Soc Sci Med. 2014;102:157-64.

64. Lemmens PH, Vaeth PA, Greenfield TK. Coverage of beverage alcohol issues in the print media in the United States, 1985-1991. Am J Public Health. 1999:89:1555-60.

65. Holmes BJ. Media coverage of Canada's obesity epidemic: illustrating the subtleties of surveillance medicine. Crit Public Health. 2009;19:223-33.

66. Kim SH, Willis LA. Talking about obesity: news framing of who is responsible for causing and fixing the problem. J Health Commun. 2007;12:359-76.

67. Goulden R, Corker E, Evans-Lacko S, Rose D, Thornicroft G, Henderson C. Newspaper coverage of mental illness in the UK, 1992-2008. BMC Public Health. 2011;11:796.

68. Kim AE, Kumanyika S, Shive D, Igweatu U, Kim SH. Coverage and framing of racial and ethnic health disparities in US newspapers, 1996-2005. Am J Public Health. 2010;100:S224-31.

69. Brownson RC, Mack NE, Meegama NI, Pratt M, Brownson CA, Dean C, Dabney S, Luke DA. Changes in newspaper coverage of cardiovascular health issues in conjunction with a community-based intervention. Health Educ Res. 1996:11:479-86.

70. McWhirter JE, Hoffman-Goetz L. Coverage of skin cancer and recreational tanning in North American magazines before and after the landmark 2006 International Agency for Research on Cancer Report. BMC Public Health. 2015:15.

71. Granner ML, Sharpe PA, Burroughs EL, Fields R, Hallenbeck J. Newspaper content analysis in evaluation of a community-based participatory project to increase physical activity. Health Educ Res. 2010;25:656-67.

72. Elstad EA, Sheridan SL, Lee JGL, Rini C, Earp JA, Brewer NT. Have screening harms become newsworthy? News coverage of prostate and colorectal cancer screening since the 2008 USPSTF recommendation changes. J Behav Med. 2014;37:1242-51.

73. McWhirter JE, Hoffman-Goetz L. North American magazine coverage of skin cancer and recreational tanning before and after the WHO/IARC 2009 classification of indoor tanning devices as carcinogenic. J Cancer Educ. 2015:30:477-81.

74. Andersson CM, Bjaras G, Tillgren P, Ostenson C-G. Local media monitoring in process evaluation. experiences from the Stockholm Diabetes Prevention Programme. J Health Commun. 2007;12:269-83.

75. Jeong M, Gilmore JS, Bleakley A, Jordan A. Local news media framing of obesity in the context of a sugar-sweetened beverage reduction media campaign. J Nutr Educ Behav. 2014;46:583-8.
76. Berry TR, Stearns JA, Courneya KS, McGannon KR, Norris CM, Rodgers WM, Spence JC. Women's perceptions of heart disease and breast cancer and the association with media representations of the diseases. J Public Health. 2016;38:e496-503.

77. Clarke JN. Cancer, heart disease, and AIDS: what do the media tell us about these diseases? Health Commun. 1992;4:105-20.

78. Duckworth K, Halpern JH, Schutt RK, Gillespie C. Use of schizophrenia as a metaphor in U.S. newspapers. Psychiatr Serv. 2003;54:1402-4.

79. Shim M, Kim Y-C, Kye SY, Park K. News portrayal of cancer: content analysis of threat and efficacy by cancer type and comparison with incidence and mortality in Korea. J Korean Med Sci. 2016;31:1231-8.

80. van der Wardt EM, Taal E, Rasker JJ, Wiegman O. Media coverage of chronic diseases in the Netherlands. Semin Arthritis Rheum. 1999;28:333-41.

81. Hellyer NE, Haddock-Fraser J. Reporting diet-related health issues through newspapers: portrayal of cardiovascular disease and Type 2 diabetes. Health Educ Res. 2011;26:13-25

82. Higgins JW, Naylor PJ, Berry T, O'Connor B, McLean D. The health buck stops where? Thematic framing of health discourse to understand the context for CVD prevention. J Health Commun. 2006;11:343-58.

83. Hoffman-Goetz L, Shannon C, Clarke JN. Chronic disease coverage in Canadian Aboriginal newspapers. J Health Commun. 2003:8:475-88.

84. Lingas EO. Promoting health: media advocacy opportunities in English- and Spanish-language masthead editorials. Am J Health Promot. 2013;27:200-4.

85. McCaw BA, McGlade KJ, McElnay JC. Online health information - what the newspapers tell their readers: a systematic content analysis. BMC Public Health. 2014;14:1316.

86. Pribble JM, Goldstein KM, Fowler EF, Greenberg MJ, Noel SK, Howell JD. Medical news for the public to use? What's on local TV news. Am J Manag Care. 2006;12:170-6.

87. Kye SY, Kwon JH, Kim Y-C, Shim M, Kim JH, Cho H, Jung KW, Park K. Cancer risk factors in Korean news media: a content analysis. Asian Pac J Cancer Prev. 2015;16:731-6.

88. Ackerson LK, Viswanath K. Media attention and public perceptions of cancer and eastern equine encephalitis. J Commun Health. 2010;35:409-16.

89. Konfortion J, Jack RH, Davies EA. Coverage of common cancer types in UK national newspapers: a content analysis. BMJ Open. 2014:4:e004677.

90. Mackenzie R, Chapman S, Johnson N, McGeechan K, Holding S. The newsworthiness of cancer in Australian television news. Med J Australia. 2008;189:155-8.

91. Peng W, Tang L. Health content in Chinese newspapers. J Health Commun. 2010;15:695-711.

92. Slater MD, Long M, Bettinghaus EP, Reineke JB. News coverage of cancer in the United States: a national sample of newspapers, television, and magazines. J Health Commun. 2008;13:523-37.

93. Campo S, Mastin T. Placing the burden on the individual: overweight and obesity in African American and mainstream women's magazines. Health Commun. 2007;22:229-40.

94. Dodgson JE, Tarrant M, Thompson JT, Young B. An analysis of infant feeding content found within the Hong Kong print media. J Hum Lact. 2008:24:317-25.

95. Donelle L, Hoffman-Goetz L, Clarke JN. Ethnicity, genetics, and breast cancer: media portrayal of disease identities. Ethnic Health. 2005;10:185-97.

96. Caburnay CA, Kreuter MW, Cameron G, Luke DA, Cohen E, McDaniels L, Wohlberg $M$, Atkins $P$. Black newspapers as a tool for cancer education in African American communities. Ethn Dis. 2008;18:488-95.

97. Cohen EL, Caburnay CA, Luke DA, Rodgers S, Cameron GT, Kreuter MW. Cancer coverage in general-audience and Black newspapers. Health Commun. 2008;23:427-35.

98. Fishman JM, Ten Have T, Casarett D. Is public communication about end-oflife care helping to inform all? Cancer news coverage in African American versus mainstream media. Cancer. 2012;118:2157-62.

99. Durrant R, Wakefield M, McLeod K, Clegg-Smith K, Chapman S. Tobacco in the news: an analysis of newspaper coverage of tobacco issues in Australia, 2001. Tob Control. 2003;12(Suppl 2):ii75-81.

100. Blake KD, Kaufman AR, Lorenzo J, Augustson EM. A descriptive study of television news coverage of tobacco in the United States: frequency of topics, frames, exemplars, and efficacy. J Health Commun. 2015;20:1415-21.

101. Bonfiglioli C, Hattersley L, King L. Australian print news media coverage of sweet, non-alcoholic drinks sends mixed health messages. Aust NZ J Publ Heal. 2011;35:325-30. 
102. Donaldson EA, Cohen JE, Truant PL, Rutkow L, Kanarek NF, Barry CL. News media framing of New York City's sugar-sweetened beverage portion-size cap. Am J Public Health. 2015;105:2202-9.

103. Fogarty AS, Chapman S. Framing and the marginalisation of evidence in media reportage of policy debate about alcopops, Australia 2008-2009: implications for advocacy. Drug Alcohol Rev. 2011;30:569-76.

104. Wakefield M, McLeod K, Smith KC. Individual versus corporate responsibility for smoking-related illness: Australian press coverage of the Rolah McCabe trial. Health Promot Int. 2003;18:297-305.

105. Wakefield M, Smith KC, Chapman S. Framing of Australian newspaper coverage of a secondhand smoke injury claim: lessons for media advocacy. Crit Public Health. 2005;15:53-63.

106. Wackowski OA, Lewis MJ, Hrywna M. Banning smoking in New Jersey casinos - a content analysis of the debate in print media. Subst Use Misuse. 2011;46:882-8.

107. Thrasher JF, Kim SH, Rose I, Navarro A, Craft MK, Davis KJ, Biggers S. Print media coverage around failed and successful tobacco tax initiatives: the South Carolina experience. Am J Health Promot. 2014;29:29-36.

108. Rissel C, Bonfiglioli C, Emilsen A, Smith BJ. Representations of cycling in metropolitan newspapers - changes over time and differences between Sydney and Melbourne, Australia. BMC Public Health. 2010;10:371.

109. Patterson C, Katikireddi SV, Wood K, Hilton S. Representations of minimum unit pricing for alcohol in UK newspapers: a case study of a public health policy debate. J Public Health. 2015;37:40-9.

110. Fogarty AS, Chapman S. Advocates, interest groups and Australian news coverage of alcohol advertising restrictions: content and framing analysis. BMC Public Health. 2012;12:727.

111. Bie B, Tang L. Representation of autism in leading newspapers in China: a content analysis. Health Commun. 2015;30:884-93.

112. Frerichs $L$, Andsager JL, Campo S, Aquilino M, Dyer CS. Framing Breastfeeding and Formula-Feeding Messages in Popular U.S. Magazines. Women Health. 2006:44:95-118.

113. Gollust SE, Lantz PM. Communicating population health: print news media coverage of type 2 diabetes. Soc Sci Med. 2009;69:1091-8.

114. Jarlenski M, Barry CL. News media coverage of trans fat: health risks and policy responses. Health Commun. 2013;28:209-16.

115. Lee $H$, Len-Rios ME. Defining obesity: second-level agenda setting attributes in black newspapers and general audience newspapers. J Health Commun. 2014;19:1116-29.

116. MacKenzie R, Chapman S, Holding S. Framing responsibility: coverage of lung cancer among smokers and non-smokers in Australian television news. Aust NZ J Publ Heal. 2011;35:66-70.

117. MacKenzie R, Imison M, Chapman S, Holding S. Mixed messages and a missed opportunity: Australian news media coverage of Clare Oliver's campaign against solaria. Med J Australia. 2008;189:371-4.

118. Siu W. Social construction of reality: the tobacco issue. Crit Public Health. 2009:19:23-44.

119. Tong A, Chapman S, Sainsbury P, Craig JC. An analysis of media coverage on the prevention and early detection of CKD in Australia. Am J Kidney Dis. 2008;52:159-70.

120. Barry CL, Brescoll VL, Gollust SE. Framing childhood obesity: How individualizing the problem affects public support for prevention. Polit Psychol. 2013;34:327-49.

121. Hamad R, Pomeranz JL, Siddiqi A, Basu S. Large-scale automated analysis of news media: a novel computational method for obesity policy research. Obesity. 2015;23:296-300.

122. Hawkins KW, Linvill DL. Public health framing of news regarding childhood obesity in the United States. Health Commun. 2010;25:709-17.

123. Shugart HA. Weight of tradition: culture as a rationale for obesity in contemporary U.S. news coverage. Obes Rev. 2013;14:736-44.

124. Freeman B. Tobacco plain packaging legislation: a content analysis of commentary posted on Australian online news. Tob Control. 2011;20:361-6.

125. Okuhara T, Ishikawa H, Okada H, Kiuchi T. Identification of gain- and lossframed cancer screening messages that appeared in municipal newsletters in Japan. BMC Res Notes. 2014;7:896.

126. Lee $H$, Lee $Y$, Park S-A, Willis E, Cameron GT. What are Americans seeing? Examining the message frames of local television health news stories. Health Commun. 2013;28:846-52.

127. Holton A, Lee N, Coleman R. Commenting on health: A framing analysis of user comments in response to health articles online. J Health Commun. 2014;19:825-37.
128. Aubrey JS. Looking good versus feeling good: an investigation of media frames of health advice and their effects on women's body-related selfperceptions. Sex Roles. 2010;63:50-63.

129. Commers MJ, Visser G, De Leeuw E. Representations of preconditions for and determinants of health in the Dutch press. Health Promot Int. 2000;15: 321-32.

130. Donelle L, Hoffman-Goetz L, Clarke JN. Portrayal of genetic risk for breast cancer in ethnic and non-ethnic newspapers. Women Health. 2004;40:93-111.

131. Hurley RJ, Kosenko KA, Brashers D. Uncertain terms: message features of online cancer news. Commun Monogr. 2011;78:370-90.

132. Fu KW, Yip PSF. Changes in reporting of suicide news after the promotion of the WHO media recommendations. Suicide Life Threat Behav. 2008;38:631-6.

133. Bonilha Dubugras MT, Evans-Lacko S, de Jesus Mari J. A two-year crosssectional study on the information about schizophrenia divulged by a prestigious daily newspaper. J Nerv Ment Dis. 2011:199:659-65.

134. Hilbert A, Ried J. Obesity in print: an analysis of daily newspapers. Obes Facts. 2009;2:46-51.

135. Martinez R, Johnston-Robledo I, Ulsh HM, Chrisler JC. Singing "the baby blues": a content analysis of popular press articles about postpartum affective disturbances. Women Health. 2000;31:37-56.

136. Stryker JE, Fishman J, Emmons KM, Viswanath K. Cancer risk communication in mainstream and ethnic newspapers. Prev Chronic Dis. 2009;6:A23.

137. Borra ST, Earl R, Hogan EH. Paucity of nutrition and food safety 'news you can use' reveals opportunity for dietetics practitioners. J Am Diet Assoc. 1998;98:190-3.

138. Franko DL, Rodgers RF, Lovering M, Fernandes C, Alfieri A, Matsumoto A, Accomando $\mathrm{K}$, Thompson-Brenner $\mathrm{H}$. Time trends in cover images and article content in Latina magazine: potential implications for body dissatisfaction in Latina women. J Lat Psychol. 2013;1:243-54.

139. Heuer CA, McClure KJ, Puhl RM. Obesity stigma in online news: a visual content analysis. J Health Commun. 2011;16:976-87.

140. Price A, Grann VR. Portrayal of complementary and alternative medicine for cancer by top online news sites. J Altern Complem Med. 2012;18:487-93.

141. Magzamen S, Charlesworth A, Glantz SA. Print media coverage of California's smokefree bar law. Tob Control. 2001;10:154-60.

142. Brannstrom I, Lindblad I-B. Mass communication and health promotion: The power of the media and public opinion. Health Commun. 1994;6:21-36.

143. Moriarty CM, Jensen JD, Stryker JE. Frequently cited sources in cancer news coverage: a content analysis examining the relationship between cancer news content and source citation. Cancer Causes Control. 2010;21:41-9.

144. O'Connor A, Casey P. What it says in the papers: an audit. Ir J Psychol Med. 2001;18:68-71.

145. McCauley MP, Blake KD, Meissner HI, Viswanath K. The social group influences of US health journalists and their impact on the newsmaking process. Health Educ Res. 2013;28:339-51.

146. Wallington SF, Blake KD, Taylor-Clark K, Viswanath K. Antecedents to agenda setting and framing in health news: an examination of priority, angle, source, and resource usage from a national survey of U.S. health reporters and editors. J Health Commun. 2010;15:76-94.

147. Hinnant A, Oh H, Caburnay CA, Kreuter MW. What makes African American health disparities newsworthy? An experiment among journalists about story framing. Health Educ Res. 2011;26:937-47.

148. Wallington SF, Blake KD, Taylor-Clark K, Viswanath K. Challenges in covering health disparities in local news media: an exploratory analysis assessing views of journalists. J Commun Health. 2010:35:487-94.

149. Ortiz SE, Zimmerman FJ, Gilliam FD. Weighing in: the taste-engineering frame in obesity expert discourse. Am J Public Health. 2015;105:554-9.

150. Gase LN, Montes C, Robles B, Tyree R, Kuo T. Media outlet and consumer reactions to promotional activities of the Choose Health LA Restaurants program in Los Angeles County. J Public Health Man. 2016;22:231-44.

151. Squiers LB, Holden DJ, Dolina SE, Kim AE, Bann CM, Renaud JM. The public's response to the U.S. Preventive Services Task Force's 2009 Recommendations on Mammography Screening. Am J Prev Med. 2011;40:497-504.

152. Smith BJ, Bonfiglioli CMF. Physical activity in the mass media: an audience perspective. Health Educ Res. 2015;30:359-69.

153. Holland K, Blood RW, Thomas SL, Lewis S. Challenging stereotypes and legitimating fat: an analysis of obese people's views on news media reporting guidelines and promoting body diversity. J Sociol. 2015:51:431-45.

154. Cooper CP, Burgoon M, Roter DL. An expectancy-value analysis of viewer interest in television prevention news stories. Health Commun. $2001 ; 13: 227-40$ 
155. Hartman MA, Nierkens V, Cremer SW, Verhoeff A, Stronks K. Is channel segmentation necessary to reach a multiethnic population with weightrelated health promotion? An analysis of use and perception of communication channels. Ethnic Health. 2015;20:194-208.

156. Hoffner C, Ye J. Young adults' responses to news about sunscreen and skin cancer: the role of framing and social comparison. Health Commun. 2009; 24:189-98.

157. Niederkrotenthaler T, Voracek M, Herberth A, Till B, Strauss M, Etzersdorfer E, Eisenwort B, Sonneck G. Role of media reports in completed and prevented suicide: Werther v. Papageno effects. Br J Psychiatry. 2010;197:234-43.

158. Weeks BE, Friedenberg LM, Southwell BG, Slater JS. Behavioral consequences of conflict-oriented health news coverage: the 2009 mammography guideline controversy and online information seeking. Health Commun. 2012;27:158-66.

159. Nicholson RA, Kreuter MW, Lapka C, Wellborn R, Clark EM, SandersThompson V, Jacobsen HM, Casey C. Unintended effects of emphasizing disparities in cancer communication to African-Americans. Cancer Epidem Biomar. 2008;17:2946-53.

160. Sun Y, Krakow M, John KK, Liu M, Weaver J. Framing obesity: how news frames shape attributions and behavioral responses. J Health Commun. 2016;21:139-47.

161. Yanovitzky I, Blitz CL. Effect of media coverage and physician advice on utilization of breast cancer screening by women 40 years and older. J Health Commun. 2000;5:117-34.

162. Smith KC, Wakefield M, Terry-McElrath Y, Chaloupka FJ, Flay B, Johnston L, Saba A, Siebel C. Relation between newspaper coverage of tobacco issues and smoking attitudes and behaviour among American teens. Tob Control. 2008; 17:17-24

163. Bigman CA. Social comparison framing in health news and its effect on perceptions of group risk. Health Commun. 2014;29:267-80.

164. Covello VT, Peters RG. Women's perceptions of the risks of age-related diseases, including breast cancer: Reports from a 3-year research study. Health Commun. 2002;14:377-95.

165. Guenther L, Froehlich K, Milde J, Heidecke G, Ruhrmann G. Effects of valenced media frames of cancer diagnoses and therapies: quantifying the transformation and establishing of evaluative schemas. Health Commun. 2015;30:1055-64.

166. Niederdeppe J, Fowler EF, Goldstein K, Pribble J. Does local television news coverage cultivate fatalistic beliefs about cancer prevention? J Commun 2010;60:230-53.

167. Riles JM, Sangalang A, Hurley RJ, Tewksbury D. Framing cancer for online news: Implications for popular perceptions of cancer. J Commun. 2015;65:1018-40.

168. Coleman R, Thorson E, Wilkins L. Testing the effect of framing and sourcing in health news stories. J Health Commun. 2011;16:941-54.

169. Frederick DA, Saguy AC, Sandhu G, Mann T. Effects of competing news media frames of weight on antifat stigma, beliefs about weight and support for obesity-related public policies. Int J Obes. 2016;40:543-9.

170. Gollust SE, Lantz PM, Ubel PA. The polarizing effect of news media messages about the social determinants of health. Am J Public Health. 2009;99:2160-7.

171. Major LH. Break it to me harshly: the effects of intersecting news frames in lung cancer and obesity coverage. J Health Commun. 2009;14:174-88.

172. Ortiz SE, Zimmerman FJ, Adler GJ Jr. Increasing public support for foodindustry related, obesity prevention policies: the role of a taste-engineering frame and contextualized values. Soc Sci Med. 2016;156:142-53.

173. Nagelhout GE, Bvd P, Hd V, Crone M, Fong GT, Willemsen MC. The influence of newspaper coverage and a media campaign on smokers' support for smoke-free bars and restaurants and on secondhand smoke harm awareness: findings from the International Tobacco Control (ITC) Netherlands Survey. Tob Control. 2012;21:24-9.

174. Niederdeppe J, Lee T, Robbins R, Kim HK, Kresovich A, Kirshenblat D, Standridge K, Clarke CE, Jensen J, Fowler EF. Content and effects of news stories about uncertain cancer causes and preventive behaviors. Health Commun. 2014;29:332-46.

175. Yeh MA, Jewell RD. The myth/fact message frame and persuasion in advertising: enhancing attitudes toward the mentally ill. J Advertising. 2015; 44:161-72.

176. Wise D, Brewer PR. Competing frames for a public health issue and their effects on public opinion. Mass Commun Soc. 2010;13:435-57.

177. Kaczynski AT, Havitz ME, McCarville RE. Altering perceptions through repositioning: an exercise in framing. Leis Sci. 2005;27:241-61.
178. Thompson TL, Robinson JD, Cusella LP, Shellabarger S. Women's health problems in soap operas: a content analysis. Womens Health Issues. 2000; 10:202-9.

179. Ye Y, Ward KE. The depiction of illness and related matters in two topranked primetime network medical dramas in the United States: a content analysis. J Health Commun. 2010;15:555-70.

180. Christenson P, Roberts DF, Bjork N. Booze, drugs, and pop music: trends in substance portrayals in the billboard top 100-1968-2008. Subst Use Misuse. 2012;47:121-9.

181. Dal Cin S, Worth KA, Dalton MA, Sargent JD. Youth exposure to alcohol use and brand appearances in popular contemporary movies. Addiction. 2008; 103:1925-32.

182. Gruber EL, Thau HM, Hill DL, Fisher DA, Grube JW. Alcohol, tobacco and illicit substances in music videos: a content analysis of prevalence and genre. J Adolescent Health. 2005;37:81-3.

183. Bell RA, Berger CR, Cassady D, Townsend MS. Portrayals of food practices and exercise behavior in popular American films. J Nutr Educ Behav. 2005; 37:27-32.

184. Bleakley A, Romer D, Jamieson PE. Violent film characters' portrayal of alcohol, sex, and tobacco-related behaviors. Pediatrics. 2014;133:71-7.

185. Durrant RH, Rome ES, Rich M, Allred E, Emans SJ, Woods ER. Tobacco and alcohol use behaviors portrayed in music videos: a content analysis. Am J Public Health. 1997:87:1131-5.

186. Eisenberg ME, Carlson-McGuire A, Gollust SE, Neumark-Sztainer D. A content analysis of weight stigmatization in popular television programming for adolescents. Int J Eat Disorder. 2015;48:759-66.

187. Eisenberg ME, Larson NI, Gollust SE, Neumark-Sztainer D. Snacking on television: a content analysis of adolescents' favorite shows. Prev Chronic Dis. 2016;13:E66.

188. Eslick GD, Eslick MG. Smoking and The Simpsons. Med J Australia. 2009;190: 637-9.

189. Hanewinkel R, Wiborg G. Smoking in contemporary German television programming. Int J Public Health. 2007;52:308-12.

190. Hanewinkel R, Wiborg G. Smoking in a popular German television crime series 1985-2004. Prev Med. 2008;46:596-8.

191. Himes SM, Thompson JK. Fat stigmatization in television shows and movies: A content analysis. Obesity. 2007;15:712-8.

192. Bergamini E, Demidenko E, Sargent JD. Trends in tobacco and alcohol brand placements in popular US movies, 1996 through 2009. JAMA Pediatr. 2013;167:634-9.

193. Atkinson AM, Sumnall H, Measham F. Depictions of alcohol use in a UK government partnered online social marketing campaign: Hollyoaks 'The morning after the night before'. Drugs Educ Prev Policy. 2011;18:454-67.

194. Primack BA, Nuzzo E, Rice KR, Sargent JD. Alcohol brand appearances in US popular music. Addiction. 2012;107:557-66.

195. Byrd-Bredbenner C. An internationally shared health frame of reference created by a television program: The Simpsons, a content analysis of health messages. Health Educ. 2004;104:18-24.

196. Roseman MG, Poor M, Stephenson TJ. A content analysis of food references in television programming specifically targeting viewing audiences aged 11 to 14 years. J Nutr Educ Behav. 2014;46:20-5.

197. Lee MJ, Gispanski L. Portrayals of eating and drinking in popular American TV programs: a comparison of scripted and unscripted shows. J Health Commun. 2016;21:593-9.

198. Robinson T, Callister M, Jankoski T. Portrayal of body weight on children's television sitcoms: a content analysis. Body Image. 2008;5:141-51.

199. Cranwell J, Murray R, Lewis S, Leonardi-Bee J, Dockrell M, Britton J. Adolescents' exposure to tobacco and alcohol content in YouTube music videos. Addiction. 2015;110:703-11.

200. Asbeek Brusse ED, Fransen ML, Smit EG. Educational storylines in entertainment television: audience reactions toward persuasive strategies in medical dramas. J Health Commun. 2015:20:396-405.

201. Cooper CP, Roter DL, Langlieb AM. Using entertainment television to build a context for prevention news stories. Prev Med. 2000;31:225-31.

202. van Hoof JJ, MDT d J, Fennis BM, Gosselt JF. There's alcohol in my soap: portrayal and effects of alcohol use in a popular television series. Health Educ Res. 2009;24:421-9.

203. Hampl JS, Wharton CM, Taylor CA, Winham DM, Block JL, Hall R. Primetime television impacts on adolescents' impressions of bodyweight, sex appeal, and food and beverage consumption. Nutr Bull. 2004;29:92-8. 
204. De la Torre-Diez I, Diaz-Pernas FJ, Anton-Rodriguez M. A content analysis of chronic diseases social groups on Facebook and Twitter. Telemed J E Health. 2012;18:404-8.

205. Donelle L, Booth RG. Health tweets: an exploration of health promotion on twitter. Online J Issues Nurs. 2012;17:4.

206. Doub AE, Small M, Birch L. An exploratory analysis of child feeding beliefs and behaviors included in food blogs written by mothers of preschoolaged children. J Nutr Educ Behav. 2016;48:93-103.

207. Moreno MA, Briner LR, Williams A, Brockman L, Walker L, Christakis DA. A content analysis of displayed alcohol references on a social networking web site. J Adolescent Health. 2010;47:168-75.

208. Pujazon-Zazik MA, Manasse SM, Orrell-Valente JK. Adolescents' selfpresentation on a teen dating web site: a risk-content analysis. J Adolescent Health. 2012;50:517-20.

209. Cole-Lewis H, Pugatch J, Sanders A, Varghese A, Posada S, Yun C, Schwarz $M$, Augustson E. Social listening: a content analysis of e-cigarette discussions on Twitter. J Med Internet Res. 2015;17:e243.

210. Stellefson M, Chaney B, Ochipa K, Chaney D, Haider Z, Hanik B, Chavarria E, Bernhardt JM, et al. Chron Resp Dis. 2014;11:61-71.

211. Lee JL, DeCamp M, Dredze M, Chisolm MS, Berger ZD. What are healthrelated users Tweeting? A qualitative content analysis of health-related users and their messages on Twitter. J Med Internet Res. 2014;16:122-30.

212. Krauss MJ, Sowles SJ, Moreno M, Zewdie K, Grucza RA, Bierut LJ, CavazosRehg PA. Hookah-related Twitter chatter: a content analysis. Prev Chronic Dis. 2015;12:E121.

213. Foley NM, O'Mahony M, Lehane EA, Cil T, Corrigan MA. A qualitative content analysis of breast cancer narratives hosted through the medium of social media. Br J Med Med Res. 2015;6:474-83.

214. Paek H-J, Kim S, Hove T, Huh JY. Reduced harm or another gateway to smoking? Source, message, and information characteristics of E-cigarette videos on YouTube. J Health Commun. 2014;19:545-60.

215. Yoo JH, Kim J. Obesity in the new media: a content analysis of obesity videos on YouTube. Health Commun. 2012;27:86-97.

216. Ghaznavi J, Taylor LD. Bones, body parts, and sex appeal: an analysis of \#thinspiration images on popular social media. Body Image. 2015;14:54-61.

217. Simunaniemi A-M, Sandberg H, Andersson A, Nydahl M. Laypeople blog about fruit and vegetables for self-expression and dietary influence. Health Commun. 2011;26:621-30.

218. Kim K, Paek H-J, Lynn J. A content analysis of smoking fetish videos on YouTube: regulatory implications for tobacco control. Health Commun. 2010;25:97-106.

219. Paek HJ, Kim KS, Hove T. Content analysis of antismoking videos on YouTube: message sensation value, message appeals, and their relationships with viewer responses. Health Educ Res. 2010;25:1085-99.

220. Boepple L, Ata RN, Rum R, Thompson JK. Strong is the new skinny: a content analysis of fitspiration websites. Body Image. 2016;17:132-5.

221. Syed-Abdul S, Fernandez-Luque L, Jian W-S, Li Y-C, Crain S, Hsu M-H, Wang Y-C, Khandregzen D, Chuluunbaatar E, Nguyen PA, et al. Misleading healthrelated information promoted through video-based social media: anorexia on YouTube. J Med Internet Res. 2013;15:137-49.

222. Seidenberg AB, Rodgers EJ, Rees WW, Connolly GN. Youth access, creation, and content of smokeless tobacco ("dip") videos in social media. J Adolescent Health. 2012;50:334-8.

223. Cole-Lewis H, Perotte A, Galica K, Dreyer L, Griffith C, Schwarz M, Yun C, Patrick $\mathrm{H}, \mathrm{Coa}$ K, Augustson E. Social network behavior and engagement within a smoking cessation Facebook page. J Med Internet Res. 2016;18:e205.

224. Kurko T, Linden K, Kolstela M, Pietila K, Airaksinen M. Is nicotine replacement therapy overvalued in smoking cessation? Analysis of smokers' and quitters' communication in social media. Health Expect. 2015:18:2962-77.

225. Myrick JG, Holton AE, Himelboim I, Love B. \#Stupidcancer: exploring a typology of social support and the role of emotional expression in a social media community. Health Commun. 2016;31:596-605.

226. Cash SJ, Thelwall M, Peck SN, Ferrell JZ, Bridge JA. Adolescent suicide statements on MySpace. Cyberpsych Beh Soc N. 2013;16:166-74.

227. Brown-Johnson CG, Sanders-Jackson A, Prochaska JJ. Online comments on smoking bans in psychiatric hospitals units. J Dual Diagn. 2014;10:204-11.

228. Harris JK, Moreland-Russell S, Choucair B, Mansour R, Staub M, Simmons K. Tweeting for and against public health policy: response to the Chicago Department of Public Health's electronic cigarette Twitter campaign. J Med Internet Res. 2014;16:e238.
229. Chung JE. Antismoking campaign videos on YouTube and audience response: application of social media assessment metrics. Comput Hum Behav. 2015;51:114-21.

230. Bissonnette-Maheux V, Provencher V, Lapointe A, Dugrenier M, Dumas A-A, Pluye P, Straus S, Gagnon M-P, Desroches S. Exploring women's beliefs and perceptions about healthy eating blogs: a qualitative study. J Med Internet Res. 2015;17:e87.

231. Paek H-J, Hove T, Jeon J. Social media for message testing: a multilevel approach to linking favorable viewer responses with message, producer and viewer influence on YouTube. Health Commun. 2013;28:226-36.

232. Beullens K, Schepers A. Display of alcohol use on Facebook: a content analysis. Cyberpsych Beh Soc N. 2013;16:497-503.

233. Carew C, Kutcher S, Wei Y, McLuckie A. Using digital and social media metrics to develop mental health approaches for youth. Adolescent Psychiat. 2014:4:116-21.

234. Jenssen BP, Klein JD, Salazar LF, Daluga NA, DiClemente RJ. Exposure to tobacco on the internet: content analysis of adolescents' internet use. Pediatrics. 2009;124:e180-6.

235. Cobb NK, Mays D, Graham AL. Sentiment analysis to determine the impact of online messages on smokers' choices to use varenicline. J Natl Cancer I. 2013;2013:224-30

236. Alvy LM, Calvert SL. Food marketing on popular children's web sites: a content analysis. J Am Diet Assoc. 2008:108:710-3.

237. Abbatangelo-Gray J, Byrd-Bredbenner C, Austin SB. Health and nutrient content claims in food advertisements on Hispanic and mainstream primetime television. J Nutr Educ Behav. 2008;40:348-54.

238. Bansal R, John S, Ling PM. Cigarette advertising in Mumbai, India: targeting different socioeconomic groups, women, and youth. Tob Control. 2005;14: 201-6.

239. Basil MD, Basil DZ, Schooler C. Cigarette advertising to counter New Year's resolutions. J Health Commun. 2000;5:161-74.

240. Belstock SA, Connolly GN, Carpenter CM, Tucker L. Using alcohol to sell cigarettes to young adults: a content analysis of cigarette advertisements. J Am Coll Health. 2008;56:383-9.

241. Bragg MA, Liu PJ, Roberto CA, Sarda V, Harris JL, Brownell KD. The use of sports references in marketing of food and beverage products in supermarkets. Public Health Nutr. 2013;16:738-42.

242. Castonguay J. Portraying physical activity in food advertising targeting children. Health Education. 2015;115:534-53.

243. Castonguay J, McKinley C, Kunkel D. Health-related messages in food advertisements targeting children. Health Education. 2013;113:420-32.

244. Chapman K, Nicholas P, Supramaniam R. How much food advertising is there on Australian television? Health Promot Int. 2006;21:172-80.

245. Guran T, Turan S, Akcay T, Degirmenci F, Avci O, Asan A, Erdil E, Majid A Bereket A. Content analysis of food advertising in Turkish television. J Paediatr Child. 2010;46:427-30.

246. Connor SM. Food-related advertising on preschool television: building brand recognition in young viewers. Pediatrics. 2006;118:1478-85.

247. Culp J, Bell RA, Cassady D. Characteristics of food industry web sites and "advergames" targeting children. J Nutr Educ Behav. 2010;42:197-201.

248. Dewe M, Ogden J, Coyle A. The cigarette box as an advertising vehicle in the United Kingdom: a case for plain packaging. J Health Psychol. 2015;20: 954-62.

249. Emond JA, Smith ME, Mathur SJ, Sargent JD, Gilbert-Diamond D. Children's food and beverage promotion on television to parents. Pediatrics. 2015;136: 1095-102.

250. Eyal K, Te'eni-Harari T. High on attractiveness, low on nutrition: An over-time comparison of advertising food products on Israeli television. Health Commun. 2016;31:988-97.

251. Folta SC, Goldberg JP, Economos C, Bell R, Meltzer R. Food advertising targeted at school-age children: a content analysis. J Nutr Educ Behav. 2006; 38:244-8.

252. Fosu I, Wicks JL, Warren R, Wicks RH. What's on the menu? Disclaimers, emotional appeals and production techniques in food advertising on childrated programs in the United States. J Child Media. 2013;7:334-48.

253. Galcheva SV, lotova VM, Stratev VK. Television food advertising directed towards Bulgarian children. Arch Dis Child. 2008;93:857-61.

254. Godbold Kean L, Prividera LC. Communicating about race and health: a content analysis of print advertisements in African American and general readership magazines. Health Commun. 2007;21:289-97. 
255. Harris JL, LoDolce M, Dembek C, Schwartz MB. Sweet promises: candy advertising to children and implications for industry self-regulation. Appetite. 2015;95:585-90.

256. Henderson VR, Kelly B. Food advertising in the age of obesity: content analysis of food advertising on general market and african american television. J Nutr Educ Behav. 2005;37:191-6.

257. Morgenstern M, Schoeppe F, Campbell J, Braam MWG, Stoolmiller M, Sargent JD. Content themes of alcohol advertising in U.S. television: latent class analysis. Alcohol Clin Exp Res. 2015;39:1766-74.

258. Movahhed T, Seifi S, Rashed Mohassel A, Dorri M, Khorakian F, Mohammadzadeh Z. Content analysis of Islamic Republic of Iran television food advertising related to oral health: appeals and performance methods. J Res Health Sci. 2014;14:205-9.

259. Paek H-J, Reid LN, Choi H, Jeong HJ. Promoting health (implicitly)? A longitudinal content analysis of implicit health information in cigarette advertising, 1954-2003. J Health Commun. 2010;15:769-87.

260. Paek H-J, Reid LN, Jeong HJ, Choi H, Krugman D. Five decades of promotion techniques in cigarette advertising: a longitudinal content analysis. Health Mark Q. 2012;29:1-17.

261. Pinsky I, Silva MTA. A frequency and content analysis of alcohol advertising on Brazilian television. J Stud Alcohol. 1999:60:394-9.

262. Rhoades $E$, Jernigan DH. Risky messages in alcohol advertising, 2003-2007: results from content analysis. J Adolescent Health. 2013;52:116-21.

263. Roberts M, Pettigrew S, Chapman K, Quester P, Miller C. The advertised diet: an examination of the extent and nature of food advertising on Australian television. Health Promot J Aust. 2013;24:137-42.

264. Scully P, Macken A, Leddin D, Cullen W, Dunne C, Gorman CO. Food and beverage advertising during children's television programming. Irish J Med Sci. 2015;184:207-12

265. Stitt C, Kunkel D. Food advertising during children's television programming on broadcast and cable channels. Health Commun. 2008;23:573-84.

266. Wilson N, Signal L, Nicholls S, Thomson G. Marketing fat and sugar to children on New Zealand television. Prev Med. 2006;42:96-101.

267. Yao T, Jiang N, Grana R, Ling PM, Glantz SA. A content analysis of electronic cigarette manufacturer websites in China. Tob Control. 2016;25:188-94.

268. Zwier S. Medicalisation of food advertising. Nutrition and health claims in magazine food advertisements 1990-2008. Appetite. 2009;53:109-13.

269. Berry TR, McCarville RE, Rhodes RE. Getting to know the competition: a content analysis of publicly and corporate funded physical activity advertisements. J Health Commun. 2008;13:169-80.

270. Chang $C$. Ideal self-image congruency as a motivator for smoking: the moderating effects of personality traits. Health Commun. 2007;22:1-12.

271. Smith KC, Cukier S, Jernigan DH. Regulating alcohol advertising: content analysis of the adequacy of federal and self-regulation of magazine advertisements, 2008-2010. Am J Public Health. 2014;104:1901-11.

272. Baek TH, Mayer M. Sexual imagery in cigarette advertising before and after the master settlement agreement. Health Commun. 2010;25:747-57.

273. Kunkel DL, Castonguay JS, Filer CR. Evaluating industry self-regulation of food marketing to children. Am J Prev Med. 2015:49:181-7.

274. Potvin Kent M, Dubois L, Wanless A. Self-regulation by industry of food marketing is having little impact during children's preferred television. Int J Pediatr Obes. 2011;6:401-8.

275. Potvin Kent M, Dubois L, Wanless A. A nutritional comparison of foods and beverages marketed to children in two advertising policy environments. Obesity. 2012;20:1829-37.

276. Potvin Kent M, Martin CL, Kent EA. Changes in the volume, power and nutritional quality of foods marketed to children on television in Canada. Obesity. 2014;22:2053-60.

277. Moodie C, Angus K, Ford A. The importance of cigarette packaging in a 'dark' market: the 'Silk Cut' experience. Tob Control. 2014;23:274-8.

278. Cortese DK, Lewis MJ, Ling PM. Tobacco industry lifestyle magazines targeted to young adults. J Adolescent Health. 2009;45:268-80.

279. Beaudoin CE. Exploring antismoking ads: appeals, themes, and consequences. J Health Commun. 2002;7:123-37.

280. Szklo AS, Coutinho ESF. The influence of smokers' degree of dependence on the effectiveness of message framing for capturing smokers for a Quitline. Addict Behav. 2010;35:620-4.

281. Arora R. Message framing and credibility: application in dental services. Health Mark Q. 2000;18:29-44.

282. Bannon K, Schwartz MB. Impact of nutrition messages on children's food choice: pilot study. Appetite. 2006;46:124-9.
283. Bassett-Gunter RL, Martin Ginis KA, Latimer-Cheung AE. Do you want the good news or the bad news? Gain- versus loss-framed messages following health risk information: the effects on leisure time physical activity beliefs and cognitions. Health Psychol. 2013;32:1188-98.

284. Kostygina G, Hahn EJ, Rayens MK. 'It's about the smoke, not the smoker': messages that motivate rural communities to support smoke-free policies. Health Educ Res. 2014;29:58-71.

285. Riker CA, Butler KM, Ricks JM, Record RA, Begley K, Anderson DG, Hahn EJ. Creating effective media messaging for rural smoke-free policy. Creating effective media messaging for rural smoke-free policy. 2015; 32: 613-624.

286. Baskin ML, Herbey I, Williams R, Ard JD, Ivankova N, Odoms-Young A. Caregiver perceptions of the food marketing environment of AfricanAmerican 3-11-year-olds: a qualitative study. Public Health Nutr. 2013;16: 2231-9.

287. Chapman S, Wakefield M. Tobacco control advocacy in Australia: reflections on 30 years of progress. Health Educ Behav. 2001;28:274-89.

288. Chapman S, Lupton D. The fight for public health: principles and practice of media advocacy. London: BMJ Publishing Group; 1994.

289. Parke H, Ashcroft R, Brown R, Marteau TM, Seale C. Financial incentives to encourage healthy behaviour: an analysis of U.K. media coverage. Health Expect. 2013;16:292-304.

290. Saguy AC, Gruys K, Gong S. Social problem construction and national context: news reporting on "overweight" and "obesity" in the United States and France. Soc Probl. 2010;57:586-610.

291. Lascu D-N, Manrai AK, Manrai LA, Amissah FB. Online marketing of food products to children: The effects of national consumer policies in high-income countries. Online marketing of food products to children: The effects of national consumer policies in high-income countries. 2013; 14: 19-40.

292. Coleman R. Framing the pictures in our heads. In: D 'Angelo P, Kuypers JA, editors. Doing news framing analysis: Empirical and theoretical perspectives. New York: Routledge; 2010. p. 233-61.

293. Chong D, Druckman JN. A theory of framing and opinion formation in competitive elite environments. J Commun. 2007;57:99-118.

294. Vliegenthart R, Van Zoonen L. Power to the frame: bringing sociology back to frame analysis. Eur J Commun. 2011:26:101-15.

295. Gunter B. Measuring bias on television: Indiana University Press; 1997.

296. Atanasova D, Koteyko N, Gunter B. Obesity in the news: directions for future research. Obes Rev. 2012;13:554-9.

297. Truong VD. Social marketing: a systematic review of research 1998-2012. Soc Mark Q. 2014;20:15-34

298. Huang J, Kornfield R, Szczypka G, Emery SL. A cross-sectional examination of marketing of electronic cigarettes on Twitter. A cross-sectional examination of marketing of electronic cigarettes on Twitter. 2014; 23 : iii26.

299. Emery SL, Szczypka G, Abril EP, Kim Y, Vera L. Are you Scared Yet?: Evaluating Fear Appeal Messages in Tweets about the Tips Campaign. Are you Scared Yet?: Evaluating Fear Appeal Messages in Tweets about the Tips Campaign. 2014; 64: 278-295.

300. Samantha Rowbotham, Merryn McKinnon, Leah Marks, Penelope Hawe. Research on media framing of public policies to prevent chronic disease: A narrative synthesis. Soc Sci \& Med. 2019;237:112428.

\section{Publisher's Note}

Springer Nature remains neutral with regard to jurisdictional claims in published maps and institutional affiliations.

Ready to submit your research? Choose BMC and benefit from:

- fast, convenient online submission

- thorough peer review by experienced researchers in your field

- rapid publication on acceptance

- support for research data, including large and complex data types

- gold Open Access which fosters wider collaboration and increased citations

- maximum visibility for your research: over $100 \mathrm{M}$ website views per year

At BMC, research is always in progress.

Learn more biomedcentral.com/submission 